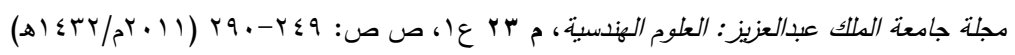
DOI: 10.4197 / Eng. 23-1.11

\title{
التخطيط الاستراتيجي لهيكلة مشروعات طبية عربية مشتركة
}

\section{سعيد على حسن القليطى، و إبراهيم عبد العزيز الضراب}

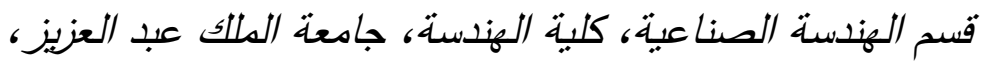

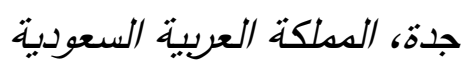

المستخلص. هذا البحث محاولة لتلمس أوجه التعاون العربي المشترك

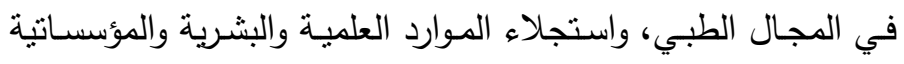

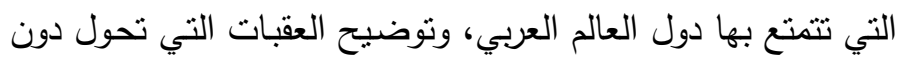

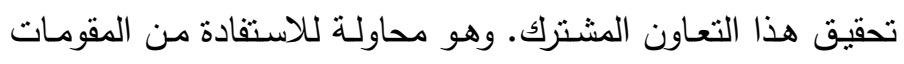

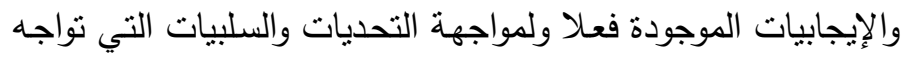

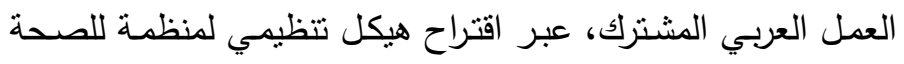

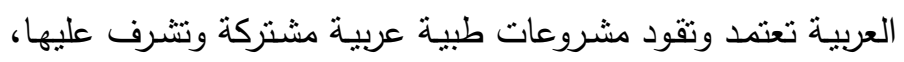

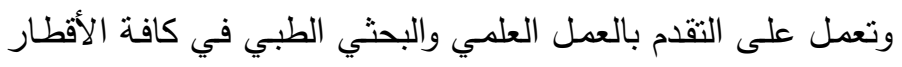

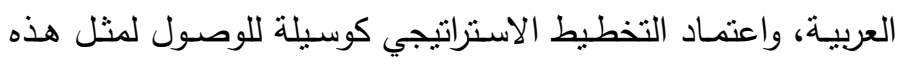

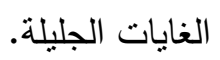

الكلمات الدفتاحية: النظطيط الاستراتيجي، الششروعات الطبية،

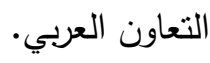

\section{1 - 1 - مقدمة}

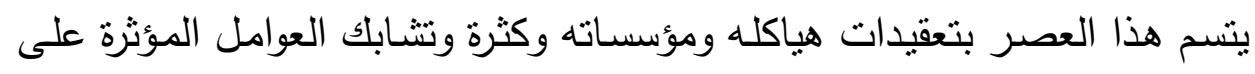

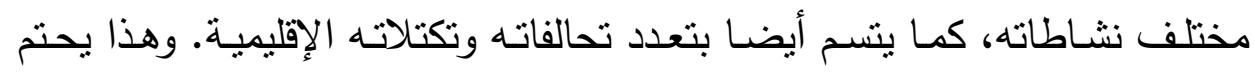


علينا الأخذ بعين الاعتبار التخطيط كوسيلة للتعامل مع هذه التعقيدات، وكأسلوب للتعامل مع هذه العوامل المتعددة وكطريقة علمية توصلنا إلى الأهداف التي نتطلع إلى تحقيقها للنهوض بالخدمات الصـحية المقدمة للمـواطن عبر الوطن العربي. ولاشك في أن التخطيط يدخل في كل المنظمات، إلا أن صورته تتضح جليّة في التخطيط للمنظمات والمؤسسات الكبرى بمختلف أنواعها، والتي تسعى من خلال التصل التخطيط لعملية تتمويـة تعود على الدولة والأفراد بالنفع والفائدة، وتتضـح بصورة أكبر في التخطيط على مستوى الدولة أو مجموعة دول "إقليم".

ولا شك أن التكتلات الإقليمية والتعاون العالمي أصبح سمة تميز عصر ما بعد الحرب العالمية الثانية. فلقد أعقب هذه الحرب ظهور منظمة الأمم المتحدة، والاتحاد الأوربي، وجامعة الدول العربية، ومنظمة الوحدة الأفريقية، ومنظمة الدول

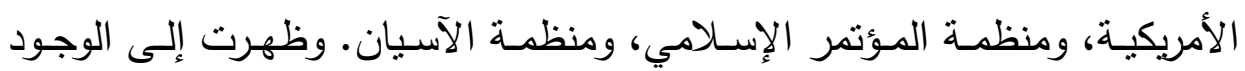

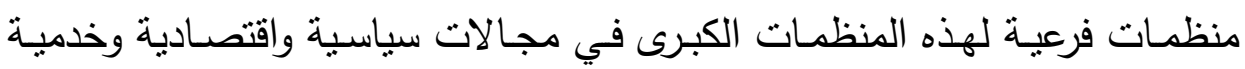
نالت من النجاح والتأثنر في عالمنا المعاصر نصيبا أكد دورها وضرورتها، وكان مجـال الرعايـة الصـحية أحـد أهـ اهتمامـات هذه المنظمـات فكـان إنشـاء منظمـة الصـحة العالميـة، على المسـتوى العـالمي واللجنـة الصـحية بالجامعـة العربيـة ثم مجلس وزراء الصحة العرب والإدارة الصحية بالأمانة العامة لجامعة الدول العربية ومنظمة الصحة العربية " قرار إنشائها مجمد " على المستوى الإقليمي العربي. وقد نوقش موضوع إنشاء منظمة عربية للصحة خلال انعقاد المؤتمر الأول

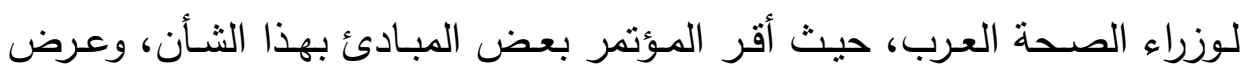

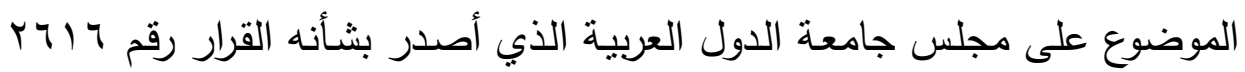

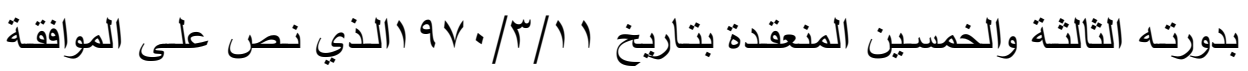
على توصية كل من لجنة الثؤون السياسية ولجنة الثؤون القانونية بالموافقة على لـى مشروع الاتفاقية. 
وعلى الـرغم مـن أن دولاً عربيـة أودعت مصـادقاتها لـدى الأمانـة العامـة

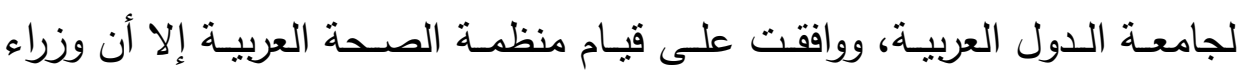
الصحة العرب حرصا منهم على عدم إنثاء أجهزة ومنظمات ينزتب على قلى قيامها

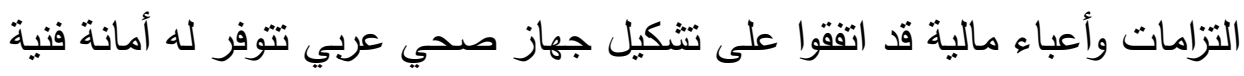

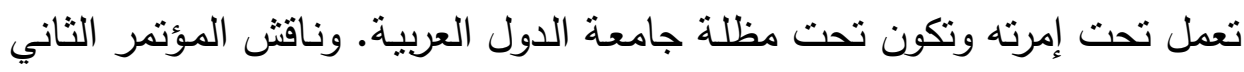

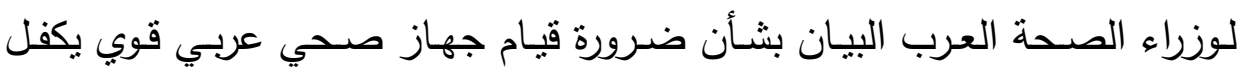

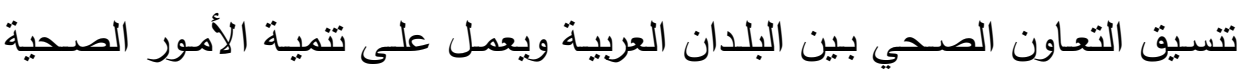

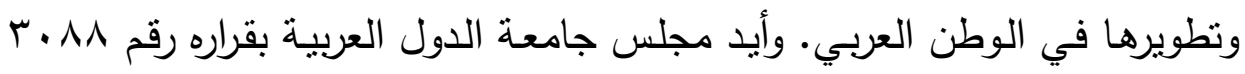

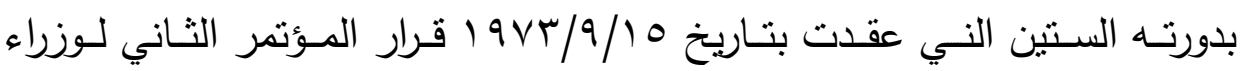

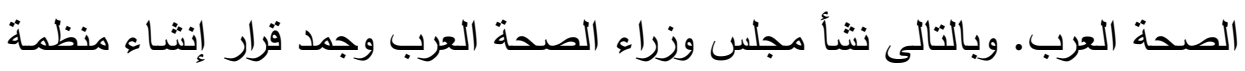
الصحة العربية.

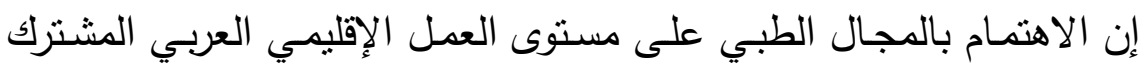

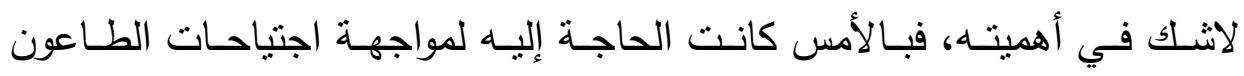

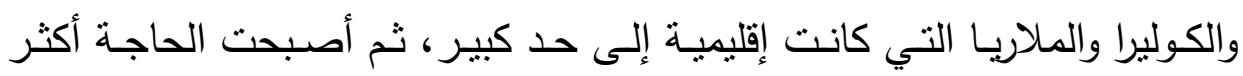

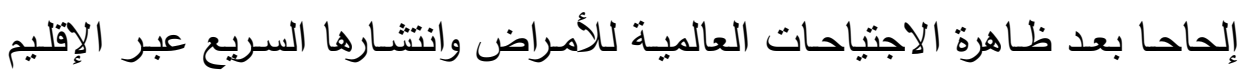

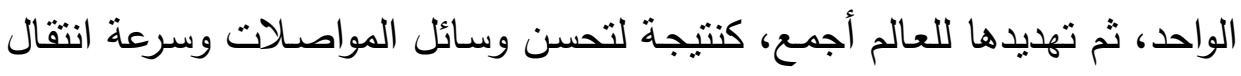

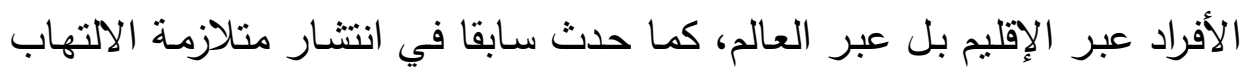

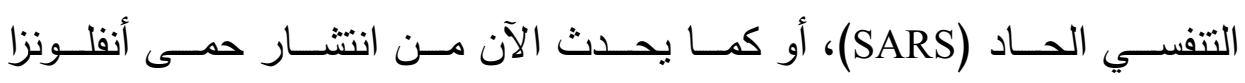

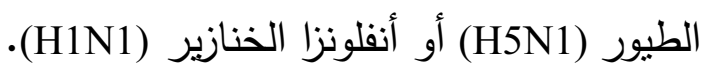

ويشهد العالم العربي تحديات صحية صعبة فى المجال الطبي ناتجة عن:

$$
\text { ( ) ( ازدياد الثفافية. }
$$

r) زيادة وعي المواطن العربي وارتفاع سقف توقعاته.

r) ارتفاع التكلفة العلاجية واستمرار تصاعدها. 
ع) تزايد الاعتمـاد على الأجهزة والمعدات التكنولوجيـة غالية الثمن، سواء في التشخيص أو العلاج.

0) النقص الحاد فى التمويل لمواجهة تكاليف النتخيل الأساسية للخدمات الصحية. 1) ضعف دعم وتطوبر الخدمات الصحية. V قلة توفير عناصرالخدمات الصحية ومكوناتها الرئيسة من كوادر بشرية مؤهلة وأجهزة ومعدات وطرق علاجية مختلفة. ^) عدم مساعدة غير المقتدرين في الحصول على الخدمات الطبية. 9) قلة تتفيذ مشروعات لتحسين الخدمات الصحية بالاشتراك مع الهيئات

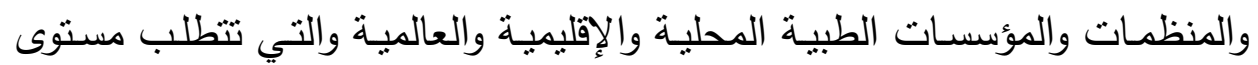
من الخدمة الصحية برقى للاعتراف بها.

• (1) ضعف العمل على تصميم وتتفيذ حملات توعية صحية. (1) (1) عدم وجود برامج تأمين صحي شاملة فى الكثير من الدول العربية.

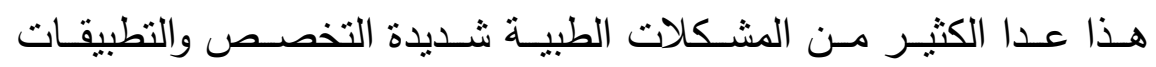
التكنولوجيـة التي تتقدم كل يوم بأجهزتها عظبمـة التعقيد سواء في التشخيص أو العلاج. وكلفة الأبحاث العلمبة والطبية التي لا مناص عنها. إلى جانب تسارع بارعة

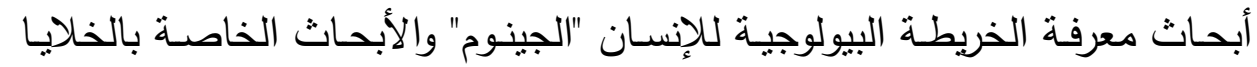
القاعدية والتطور في الهندسة الوراثية وتطبيقات الاستسـاخ، بالإضـافة إلى جنوح العالم نحو الأسلحة البكتيرية والبيولوجية والذى يحتم علينا التصدى لله عبر امتلاك وله وسائله.

كل هذه المسؤوليات والمهام والتوجهات الصحية والطبيـة التي لا بستطيع

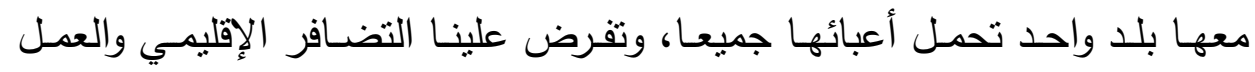
المشترك كوسيلة لتحسين صحة المواطن العربي، والسير إلى جانب العالم ومقارعة 
قواه. وتزبد من أهمية وضرورة إقامة مشروعات طبية مشتركة عبر الإقليم العربي، وتؤكد حتمية الأخذ بالتخطيط الاستراتيجي لهيكلة مشروعات طبية عربية مشتركة.

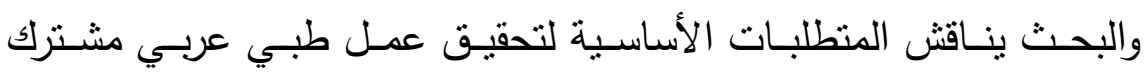
ومشروعات طبية عربية مشتركة، ويحدد مسؤوليات كل من الحكومات والمؤسسات

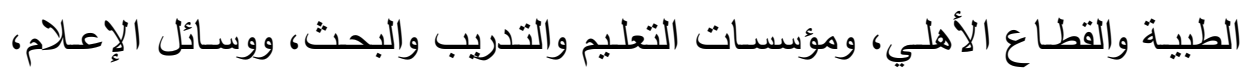
والمواطنين جمبعا في تحقيق ذلك الهدف على الوجه الأكمل. ويعرض البحـث التخطيط الاسـتراتيجي كأسـلوب للتحرك وتعبئة وتركيز الجهـود لمواجهـة التحـديات الصـحية المعاصـرة على مسـتوى الـوطن العربـي، والاستفادة من الفرص الموجودة في البيئة الخارجية، ويواجه تحدياتها، والذي يأخذ في الحسبان نقاط الضعف ونقاط القوة في البيئة الداخلية سعيا لتحقيق الأهداف المرجوة، حيث يتم في المرحلة الأولى تحديد المفاهيم الأساسية لعملية التخطيط

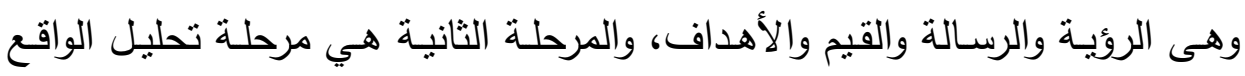

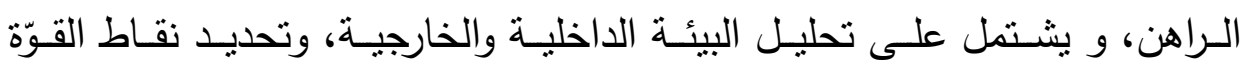
والضـعف والفرص والمخـاطر ، وكذلك تحديـد المحـاور الاسـتراتيجية، ثم البـرامج

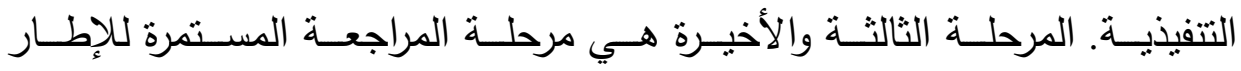
الاسـتراتيجي، والتعرف على التعديلات الـلازم إدخالها على الأطـر الاسـتراتيجية

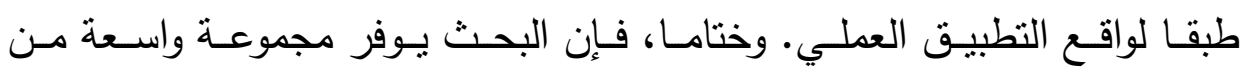
الاستتناجات والتوصيات التي تعطي أفضل النتائج والتوقعات لتحقيق المشروعات الطبية العربية المشتركة.

\section{ץ - واقع العمل الطبي العربي المشترك}

اتخذ العمل الطبي العربي المشترك أشكالاً متتوعة من التراكيب والتحركات، وظل يتطور مـع التطور الطبي العالمي وما شهده العالم العربي من أحداث إلى 
وقتتا الحاضر • وبنظرة على أمثلة المشروعات الطبية المشتركة القائمسة في العالم العربي نراهـا متمثلـة في حصـول كثير من الأطبـاء العـرب وأطقم العمل الطبي المختلفة من الأقطار العربية المتعددة على درجاتهم العلمية وخبراتهم العملية من جامعـات ومعاهـد مصـرية، وأن الكثيـر مـن الأطقم الطبيـة المصـرية والسـورية والسـودانية قد انتقلت للعمـل بدول الخليج العربي، وهنـاك أيضـا اسـتمارات في وهي المجال الطبي تجاوزت حدود البلد الواحد إلى دول عربية متعددة مثل المستشفى السعودي الألماني ومستشفى المغربي للعيون، ومعمل البرج، ومركز "علاج". كما

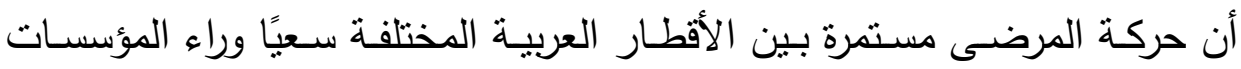
الطبية التي حازت على ثقتهم وأثتتت جدارتها بإنجازاتها الطبية المتميزة مثل مركز الكلى والمساللك البولية بالمنصورة ومدينة الملك عبد العزيز الطبية بالمملكة العربية السـودية وغيرهـا، كما قامت جامعة الدول العربية بإنشـاء مجلس لوزراء الصحة العرب ولجنة الصحة العربية.

\section{r - 1 العدل الطبح العربي المشترك عبر جامعة الدول العربية " لمحة تاريخية"} تطلع العرب للعمل المشترك فيما بينهم مبكرا في مجالات عدة منها بطبيعة الأمر العمل الصحي، ولكن هذا العمل المشترك ظل بطيئا متعثرا وفي أغلبه ورقيا

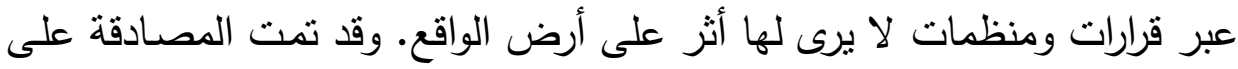

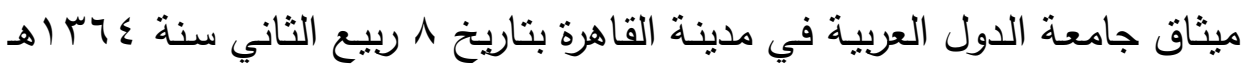
الموافق r r آذار (مارس) هـ 9 (م. وقام بذلك ممثلو الدول العربية التالية: سوريا،

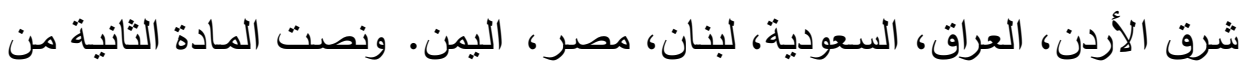
الميثاق على ما يلي: "الغرض من الجامعة نوثيق الصـلات بين الدول المشتركة فيها، وتتسيق خططها السياسية، تحقيقا للتعاون بينها صيانة لاستقلالها وسيادتها، والنظر بصفة عامة في شؤون البلاد العربية ومصالحها". وكذلك كان من أغراضها 
تعاون الدول المشتركة فيها تعاونا وثيقا بحسب نظم كل دولة منها وأحوالها في

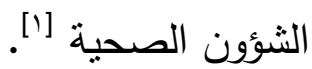

r-1 - الإدارة الصحية بالأمانة العامة لجامعة الدول العربية

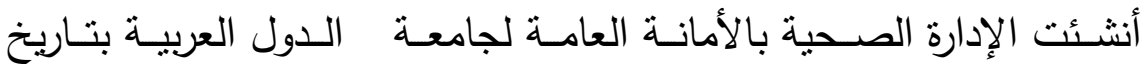

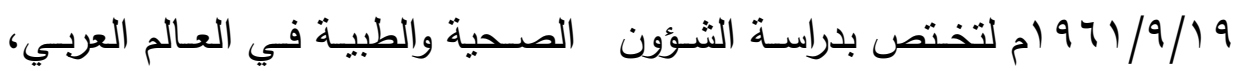
ومؤتمرات اتحادي الأطباء والصيادلة العرب، وكذلك الندوات والاجتماعات الصحية الدوليـة. وتقوم الإدارة بتتسيق الجهود وتوفير وسائل التعاون بين البلدان العربية، وتعمل على توحيد دساتير الأدوبية وبرامج دراسـة الطب في البلاد العربية والإعداد

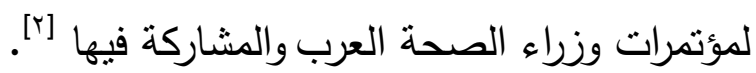
r- - r - مؤتمرات وزراء الصحة العرب خلال الفترة الواقعة بين عامي 979 و و و 9 ام عقد وزراء الصحة العرب العرب أربعة مؤتمرات، وبيكن تلخيص مواضيع القرارات التي صدرت عن هذه المؤتمرات

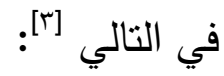
- الدعم الطبي للثورة الفلسطينية. - الأحوال الصحية فى الأراضي العربية المحتلة. - مشكلة الدواء العربي. - مشروع تأسيس منظمة صحة عربية. - التعليم الطبي ومتطلباته فى البلدان العربية. ـ الإجراءات الوقائية الواجب اتخاذها في البلدان العربية لدرء خطر الكوليرا. - الترشيحات لمراكز المجلس التتفيذي لمنظمة الصحة العالمية. - المركز العربي لبحوث الإصابات. - استخدام اللغة العربية كلغة عمل في الهيئة الصحية العالمية. 
- مشـاريع القوانين العربيـة الموحدة لمزاولـة مهنـة الطب البشـري ومهنة طب وجراحة الأسنان ومهنة الطب البيطري ومهنة الصيدلة في البلاد العربية. - إنشاء مجلس وزراء الصحة العرب. - توثيق التعاون ونبادل الخبرات والمعونات الطبية والمادية بين الدول العربية. - نظم الإدارة الصحية والتأمين الصحي. - السماح للأطباء العرب بممارسة مهنة الطب في أي بلد من البلدان العربية. - المراكز التذربيية وإعداد المساعدين الطبيين لمهنة الطب فى البلدان العربية. - التعاون الصحي العلمي بين الدول العربية والدول الأفريقية. - التعليق على برامج وميزانيات الهيئة الصحية العالمية. - إنشاء اتحاد عربي لجمعيات وهيئات رعاية ذوى الاحتياجات الخاصـة في الوطن العربي. r- - r-r مجلس وزراء الصحة العرب

ناقش المؤتمر الثالث فكرة إنشاء مجلس وزراء الصحة العرب وهو نوعية جديدة لأجهزة العمل العربي المشترك وأعد نظامه الأساسي الذي أقره بعد ذلك فئك المؤتمر الرابع لوزراء الصحة العرب. ثم أحيلت فكرة إنشاء مجلس وزراء الصحة

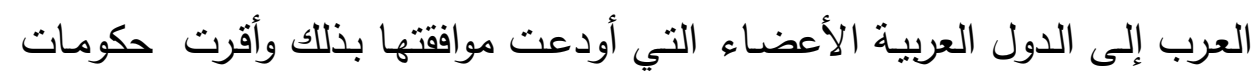
الدول العربية إنشاء هذا المجلس وأحيل نظامـه الأساسي لمجلس جامعـة الدول

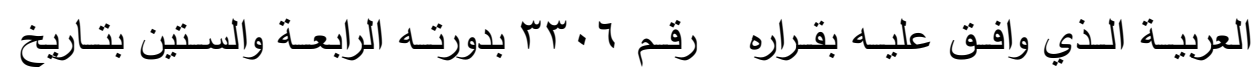
$.19 \times 0 / 9 / \varepsilon$

ومنذ قيام مجلس وزراء الصحة العرب كان المجلس مستقلا في قراراته التي يتخذها باعتباره مجلسًا يتألف من وزراء مختصين يعملون في جهاز عربي تقره

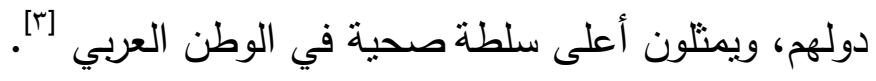




$$
\text { r-1 المجلس العربي للاختصاصات الطبية }
$$

إن الحصول على شهادة أجنبية عالية كمسوغ لإعطاء لقب الاختصاصي لهـي للطبيب لا يشترط رصيدًا من التدريب الوافي الذي يتيح للطبيب القيام بهذا الدور لإنه

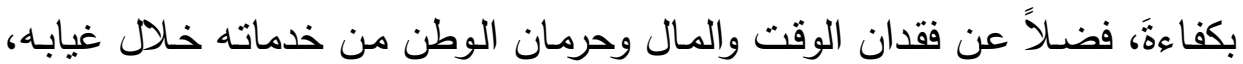
إضـافة للصعوبات الكبيرة التي يعـاني منها الطبيب بإيجـاد مركز تدريب بمنحسه

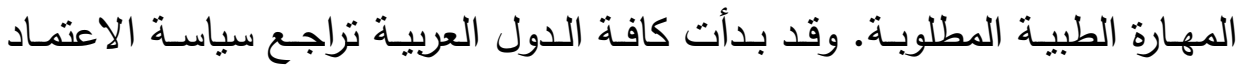
الخاصة بالحصول على هذه الثهادة الأجنبية ، وتصدى وزراء الصحة العرب لهذا الموضوع، حيث أصدر مجلس وزراء الصحة العرب في دورته الثالثة المنعقدة في

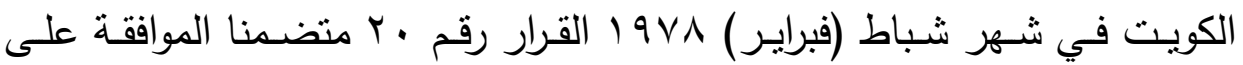
مشروع تأسيس المجلس العربي للاختصاصات الطبية. وِيهدف المجلس العربي للاختصاصات الطبية إلى:

• العمل على تحسين الخدمات الطبية في الوطن العربي عن طريق رفع المسـتوى العلمي والعملي للأطبـاء العـاملين في مختلف الاختصاصـات وذلك بالتعاون مع المؤسسات التعليمية المعنية.

وضع مواصفات التدريب المعترف به من خلال إعداد الاختصاصي في فروع الطب المختلفـة مـن كافـة نواحيـه والعمـل على اسـتكماله ومراقبـة احتفاظـه بمستواه المقرر مع مراجعته دوريا لمواكبة التقدم الطبي. وضـع أسس تقييم المستوى العلمي والفني والمهني للأطباء الذين يرغبون في ممارسة الاختصاصات بعد إنهاء فتزة التدريب المعترف بها. ومهام المجلس هى [؛]: تشكيل مجالس علميبة لكل الاختصاصـات الطبيـة بدءًا بالفروع الرئيسـة لتوصيف التدريب المطلوب من كافة نواحيه واعتماد أسس التقييم. 


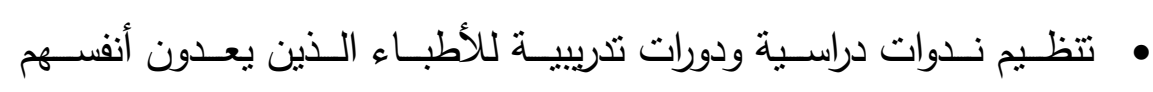
للاختصاص بالتعاون مع المؤسسات الطبية والتعليمية في الوطن العربي. مساعدة الأطباء الاختصاصبين على منابعة التعليم بصورة مستترة لتطوير معلوماتهم وخبراتهم وتحديثها بوسائل التعلم الذاتي وسائر الطرق الحديثة. • إصدار النشرات والمطبوعات التي تتفذ أهداف المجلس ومهامه. • وضـع أسس شـهادات الاختصـاص للأطباء الذين تتوافر فيهم الثـروط التي يضـعها المجلس والذين يجتازون بنجاح الامتحانـات التي تعقدها المجالس العلمية التابعة لها.

r - العمل الطبح العبي المشترك عبر التعليم الطبي والتلديب ونقل الخبرات هناك الكثير من الجهود عبر الوطن العربي في مجال التعليم الطبي، الذي

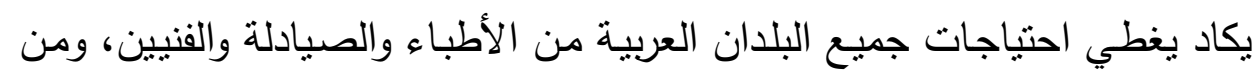

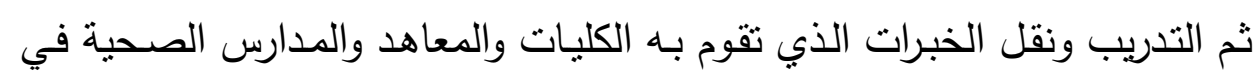
كافة التخصصات. وهناك أيضا تبادل للبرامج التعليمية والزيارات يتم عبر الوطن بـن العربي وإن كان بصورة محدودة .

غير أن هذا الجهد يتنم على مستوى كل بلد على حدة، ولا يتم بطريقة

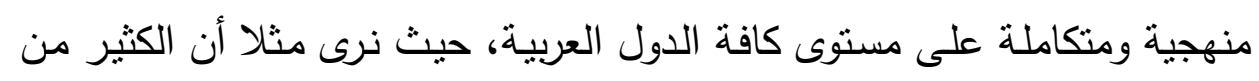
برامج التدريب للعمالة الطبية في بعض البلدان العربية تتحصر في أهل البلد نفسه ولا تمتد لتتمية قدرات العمالة الوافدة سواءً كانت عربية أو أجنبية.

\section{r - r مراكز طبية متخصصة}

هناك بعض المؤسسات الطبيـة الكبرى والمتخصصسة وصلت إلى مستوى تقني طبي عال وعلى مستوى عالمي، واستطاعت أن تصل بدقة عملها لأن تصبح قبلة للمواطن العربي عند حاجته لخدماتها وعلى سبيل المثال: 


\section{• - مركز الكلى بالمنصورة.}

• مدينة الملك عبد العزبز بالحرس الوطني بالرباض.

• التجربة الرائدة لدولة الإمارات العربية وإمارة أبو ظبي على وجه التحديد

في إنثاء مستشفى أبو ظبي المتنقل "كأول مستشفى متتقل في العالم".

• مراكز سلاسل الأمل للدكتور مجدي يعقوب بصعيد مصر .

\section{r - الخبرات البشربية}

شـهدت السـاحة العربية تحركًا في الخبرات البشرية الطبيـة والعلاجيـة على

نطاق واسع وخصوصًا في الآونة الأخيرة، ويمكن تلخيص ذلك بالتالي:

• الاسـتعانة بـالخبرات الطبيـة مـن مصـر على هيئـة "بـرامج زيـارات"

لمسنشفيات دول الخليج العربي والمغرب العربي والدول الإفريقية.

انتقال خبرات طبية وتمريضية وفنية للعدل من مصر وسوريا والسودان

$$
\text { إلى دول الخليج العربي ودول المغرب العربي. }
$$

• انتقال المرضـى للعـلاج بين مختلف الدول العربية، بحثا عن خبرات

طبية موثوق بها، أو إمكانات تشخيصية أعلى وأكمل.

• الاستعانة بالخبرات الطبية العربية المهاجرة خارج نطاق الإقليم العربي من كبار الأساتذة والعلماء.

r - مؤسسات طبية خاصة تعمل د/خل الوطن العربي

استطاعت بعض المؤسسات الطبية الخاصـة أن تتجاوز حدود بلدها وتمد عملها داخل الوطن العربي بإنشاء فروع لها في أكثر من بلد عربي، على سبيل المثال:

المستشفى السعودي الألماني. 


$$
\begin{aligned}
& \text { سعيد على حسن القلبطى و إبراهيم عبد العزيز الضراب } \\
& \text { • مستشفى المغربي للعيون. }
\end{aligned}
$$

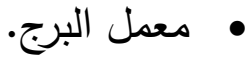

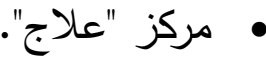

\section{r - r التعاون الإقليهي للتصدي للكوارث الصحية والإنسانية}

نسـارع الدول والحكومـات العربيـة بتقديم يـد العـون الصـحي في مواجهـة

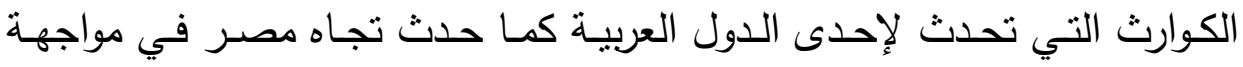

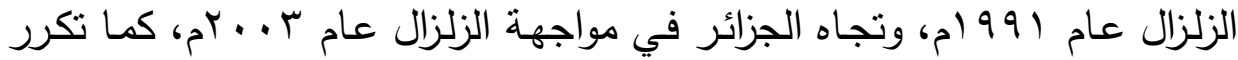

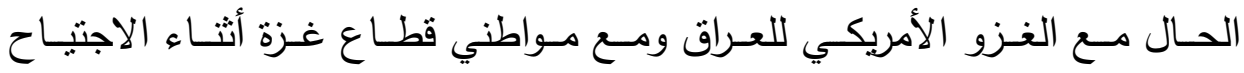
الصهيوني الأخير للقطاع.

\section{ب- أهمية العمل الطبي العربي المشترك}

تتجلى أهية العمل العربي المشترك في توحيد الجهود للارتقاء بالخدمات

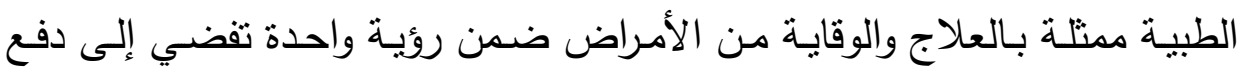

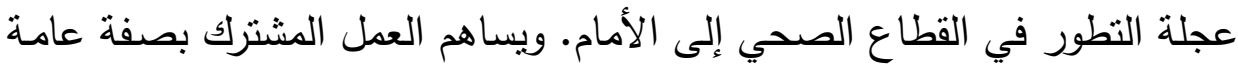
فى: تكثيف الجهود، تعظيم الفائدة، ضمان التمويل، تكامل الموارد، توسيع السوق،

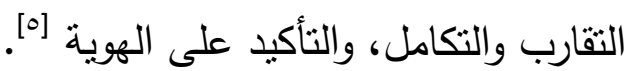

وتظهر أهمية العمل العربي المشترك في مجال الصحة فى الآتى:

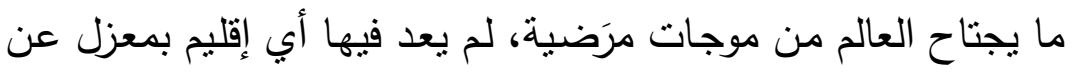

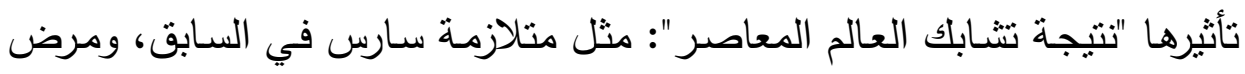

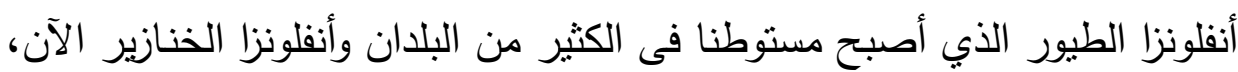

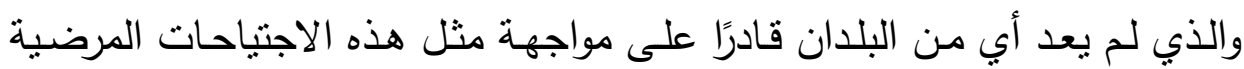
منفردا، كما أن هذه المواجهة المنفردة أصبحت غير فعالة وغير مؤثرة. 


\section{• الكلفة المتزايدة والمستمرة للخدمات الطبية.}

التقدم في العلوم والبحوث الطبية والتي لا يستطيع معها أي بلد بمفرده

أن يتصدى لها.

الانتقـال الســل والمسـتمر للأفـراد بـين البلـدان العربيـة - والمنتظـر

ازدياده- والذي يحتم ضرورة وضع سياسة صحية عربية موحدة.

• حاجة بعض البلدان العربية للخبرات الطبية فى بلدان عربية أخرى.

• ضرورة تطوير البحوث الطبية والدوائية فى كل مجالاتها.

ضرورة تقدم صناعة الدواء، بضمان عناصرها.

• الأمن القومي والإقليمي عبر مواجهة الأسلحة البكتيرية والبيولوجية.

\section{؟ - التخطيط الاستراتيجي لتحقيق العمل الطبي العربي المشترك}

يمكننا تعريف التخطيط عموما بأنه رسم الصورة المستقبلية للمجتمع وذلك من خـلال تحديد العمل الذي ينبغي اتباعه لتحقيق أهداف معينة في فترة زمنية محددة، وبمكننا كذلك إجمال أهمية التخطيط في تحديد مسارات العمل في مجالاته المختلفة، واختصار الوقت والجهد والزمن في عملية التتفيذ وفي عملية التطوير •

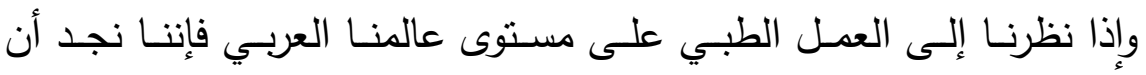
التحديات التي تواجه المجتمعات العربية في المجال الطبي بكافة الأطر البحثية والتعليمية والتدربيية أو في مجال العمل الطبي الإكلينيكي وقاية أو علاجا تحتاج إلى رؤبـة عربيـة شـاملة وتخطيط استراتيجي إقليمسي منكامل، فرغم أن إمكانيات العمل الطبي العربي المشترك متعددة ومتتوعة وعابرة للحدود إلا أن هذه الجهود مازالـت مشـتتة وفرديـة ، لا نشـملها خطـة اسـتراتيجية واحدة، ولا تظللهـا هيكلـة 
مؤسسية تحكم عملها وتقود خطاها وتوحد مجهودها وفق تخطيط علمي ومنهجية منظمة للوصول إلى أهداف محددة وواضحة.

ويتضــمن التخطـيط الاسـتراتيجي مجموعـة مـن المراحـل نلخصــها فـي

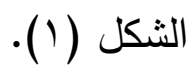

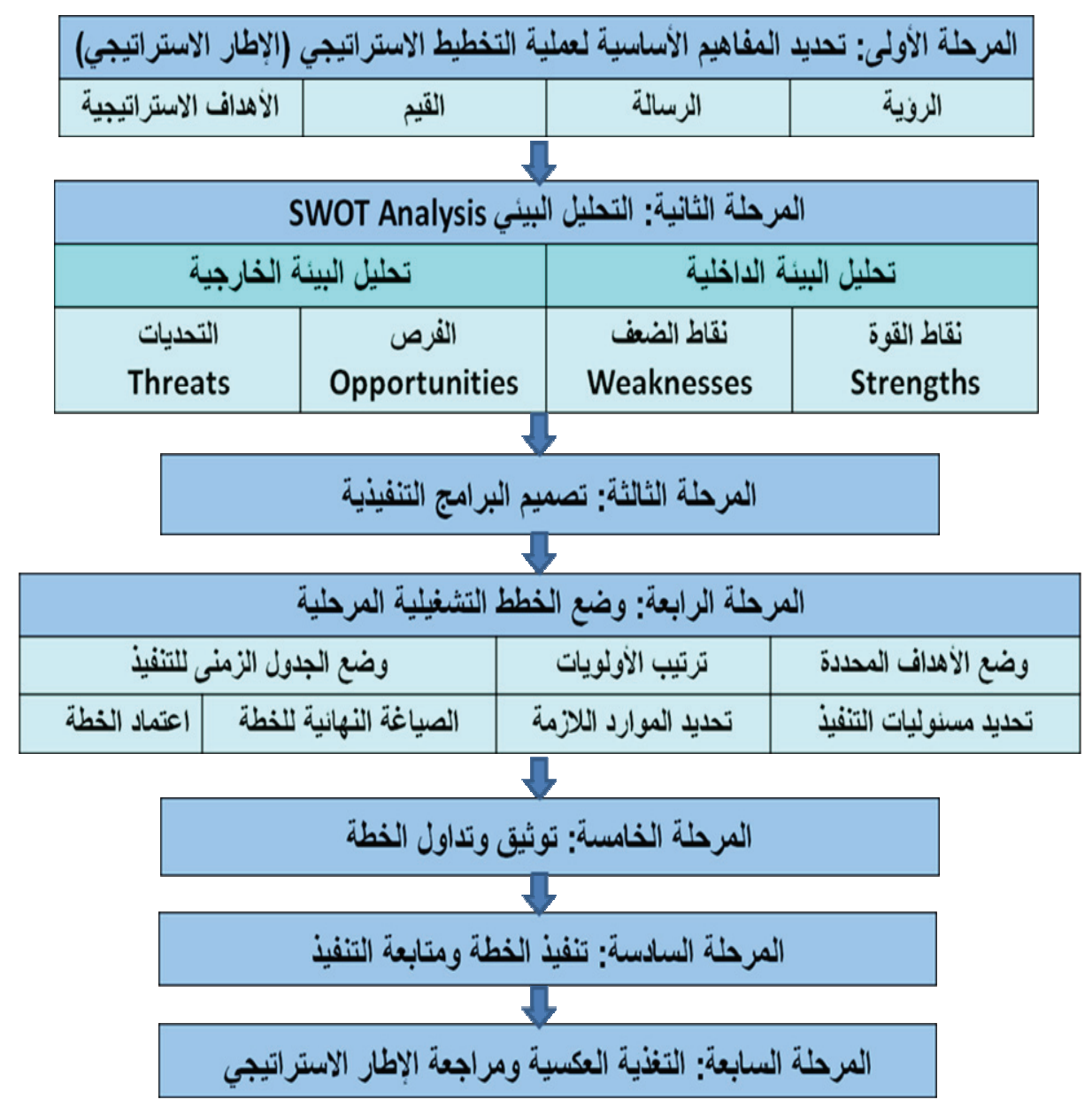

شكل (1). المراحل المختلفة لعملية التخطيط الاستراتيجي. 


\section{؛ - 1 - تحديا الدفاهيم الأساسية لعطلية التخطيط (الإطار الاستراتيجي)}

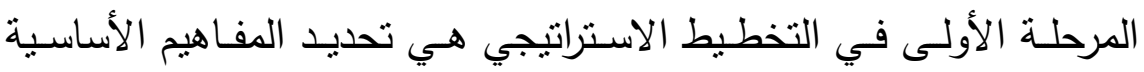

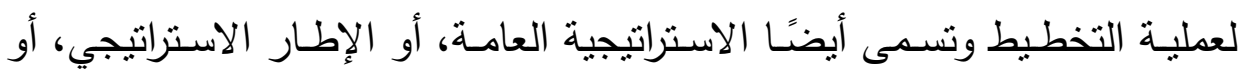

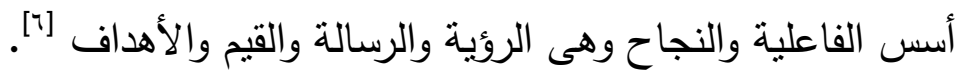

$$
\text { - - الرئية }
$$

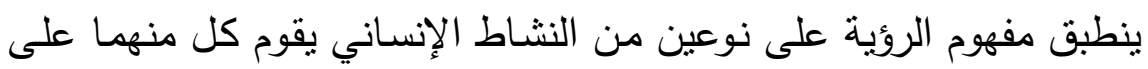

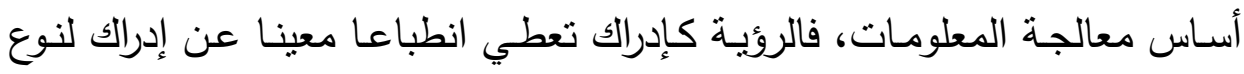

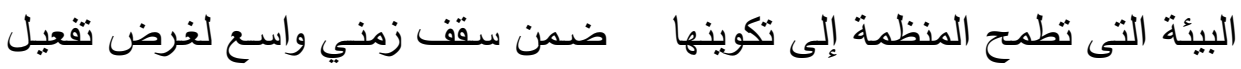

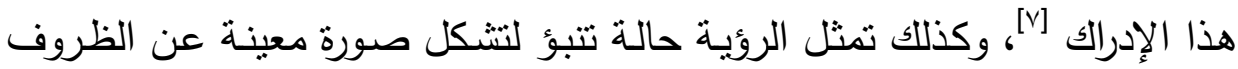

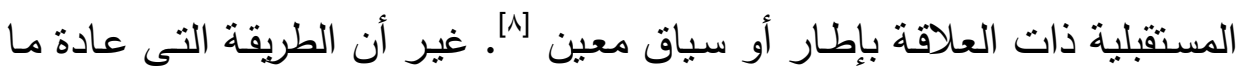

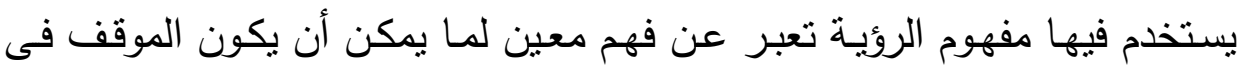

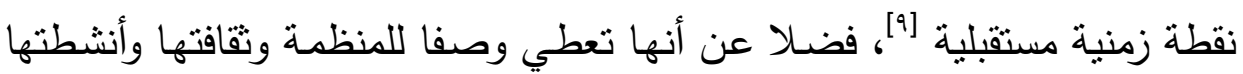
المستقبلية [• (1)

إن الرؤية هى حقيقة مستقبلية جديدة ومرغوبة يمكن إيصالها إلى كل أرجاء

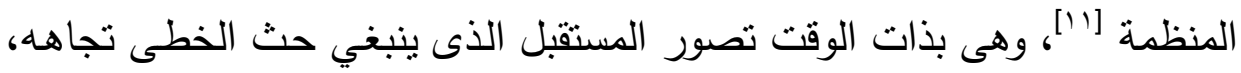

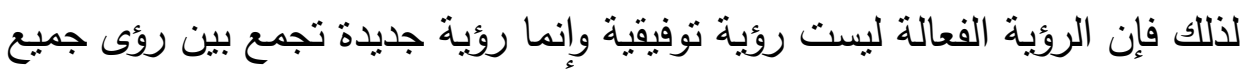

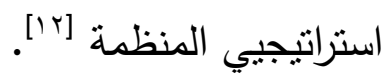

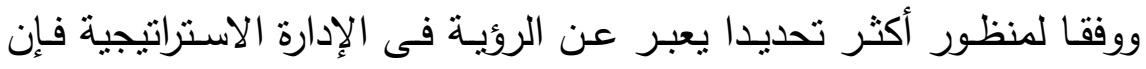

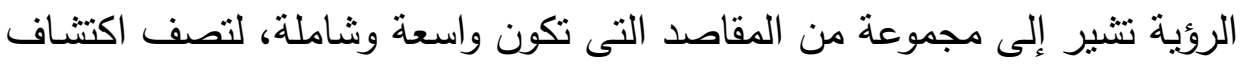

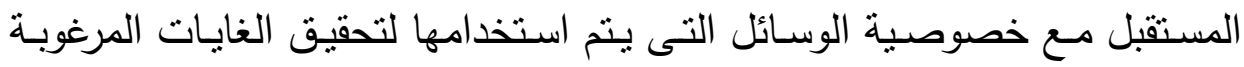

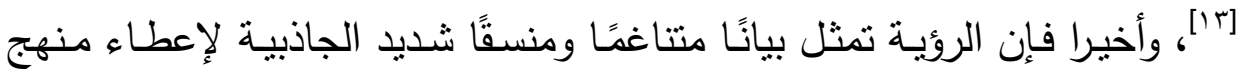

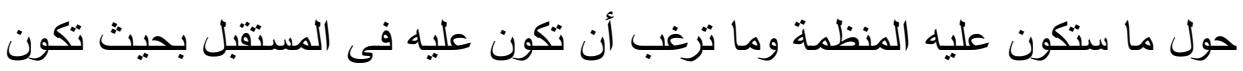

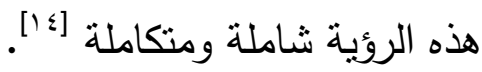




$$
\text { سعبي على حسن القليطى و إبراهيم عبد العزيز الضراب }
$$

أى إن الرؤية تصف المستقبل وماذا نريد أن نكون بعد فترة زمنية محددة.

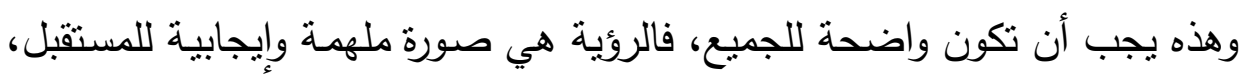

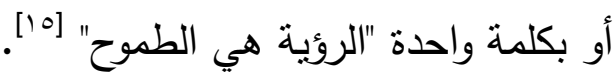

\section{أهمبية الرئية للمنظمة}

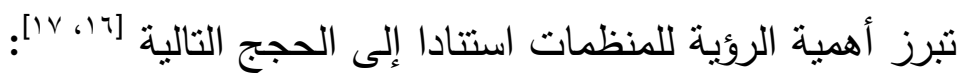

- ضعرورة أن تراقب المنظمـة الأعمال وتنبطر عليها فى بيئة أصبحت

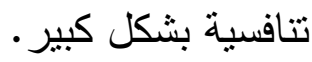

- - تُبرز الروية الحاجة إلى استراتيجيات إبداعية مستندة إلى مزايا تفوق حقيقية.

- تبعـد المنظمـة عـن حـالات الفشـل المصـاحبة لعـدم امـتلالك منظـور

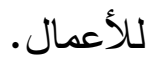

- تحث على إحداث تغييرات جوهرية فى ثقافة وسلوك المنظمة.

- تبنى حالة من التفاعل الإيجابي بين جميع العاملين بالمنظمة.

- تسـاعد على توضيح الاتجاه العام للتغيير حيث إنها تبسط القرارات

التفصيلية.

- - تحفز على اتخاذ الأفعال الصحيحة وفق الاتجاه المعلن.

- تساعد على تتسيق مختلف أفعال العاملين إذا ما كانت الرؤية مستلهمة

من قبلهم. - من

\section{مكونات اليؤية وأبعادها}

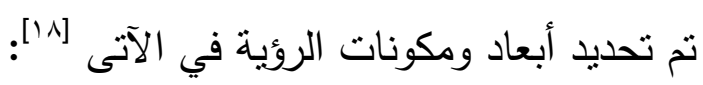

- مجال الأعمال: وهذه تعطي مزيج الأعمال الذى اختارته المنظمة وتتابع

تقدمها فيه، إنها تنتل اقتطاع مجالات للابتعاد عنها وأخرى للاخول إليحها. 
- حجم الأعمال: يعتبر الحجم بعدا مهما فى رؤيسة المنظمة حيث يساهم فى اختيار حقيبة الأعمال ونوع التنظيم وأساليب الإدارة. ئنئ.

- الأسـواق والمنتجـات: اختيـار الأسـواق والمنتجـات فـى ضـوء اعتبـارات عناصر روية المنظمة الأخرى وفى ضوء الرسالة والقيم. - التركيز على المنافسة: وهى تجيب على سؤال: كيف سنتنافس المنظمة

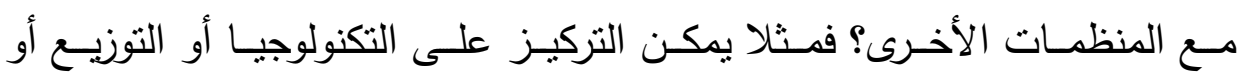
الخدمات أو غيرها.

- السمعة والعلاقات: وهي تعطى الديناميكيـة الضـرورية والأساسية لنقل الرؤية إلى واقع ملموس. - التنظيم والثقافة التنظيمية: وهي جميعها مفاتيح أساسية للنجاح فى نقل الروية إلى واقع فعلي.

\section{معابيز وخصائص الرئية الفعالة}

يثير العديد من الباحثين إلى أن خصائص الرؤية الفعالة والجيدة والتى تلهح

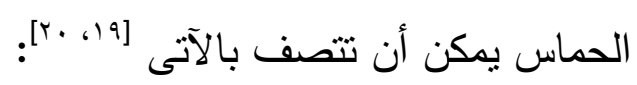

- يجب أن تكون الرؤية مختصرة وبسيطة وواضحة تحمل فى طياتها حلما كبيرا يجسد واقعية ملموسة. - تثير التحدي للمنظمة بصورتها الشمولية، حيث برى الجميع أن العمل الجاد والمثابر سيجعل من المنظمة حالة متميزة تلبي طموحاتهم. - أن ترضي وتلبي جميع تطلعات وطموحات المتعاملين مع المنظمة بصورة مباشرة أو غير مباشرة. - أن نكون روية المنظمة منسجمة مع رسالتها وقيمها. 
- - أن تعطي رؤية المنظمة إمكانية استخدام مؤشرات للفحص والتأكد من صدق التوجه لتحقيقها والعمل فى إطارها.

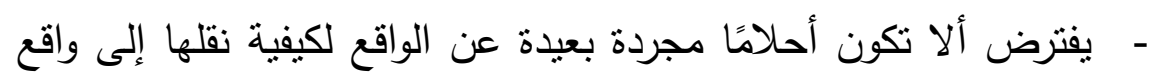
ملموس، وهذا الأمر يتطلب فهما عميقا للأعمال والأسواق والمنافسين. - - أن تكون ملهمة ومثيرة للتحدى والحماس لجميع المستويات الإدارية ولجميع العاملين وأن تثحذ همم وقوى الجميع للالتزام بها. - يمكن ترجمتها ونقلها إلى أهداف مترابطة ترسم صورة المستقبل المرغوبة للمنظمة. - - أن تكون لها قوة إيصال واسعة لكي تشكل جزءًا أساسيا من ثقافة المنظمة، بحيث تصبح منظورا يتقاسمه الجميع وينم فهمه بصورة موحدة. - يفترض ألا تكون الرؤية مجرد شعارات مستقبلية بعيدة عن الواقع القائم، بل أن تكون عملية تكامل ما بين الحاضر والمستقبل. مثال للرؤيـة في نطـاق بحثنـا: "مجتمـع عربـي متميز فـى العمل الطبي

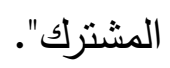

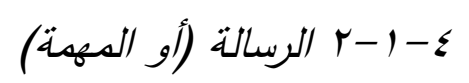

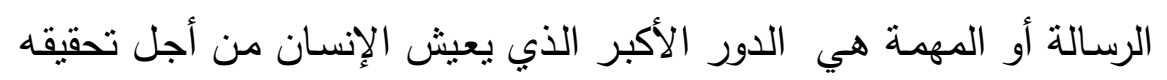

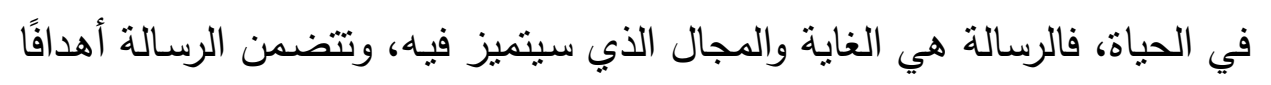

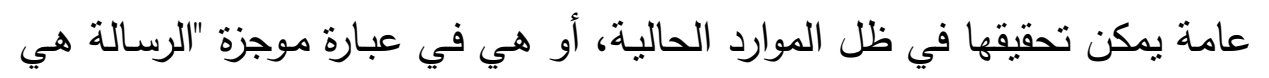

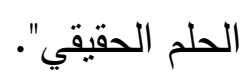

$$
\text { فوائد وجود الرسالة [1r] }
$$

ا - تعمل على توحيد الجهود لتحقيق الأهداف الثاملة. r- تحدد المعيار الذي بستخدم في تخصيص الموارد بين الاستخدامات البديلة. 
r- تسهل عملية اتخاذ القرارات لوجود مرشد واضح لها.

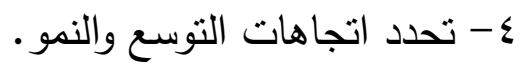

0- تساعد على تصميم وسائل إعلانية تركز على نواحي القوة. 7- تشعر العاملين بجدية الإدارة العليا وإصرارها على تحقيق أهداف معينة.

\section{المكونات الرئيسية للرسالة}

ا- النشاط: أن تحدد بوضوح طبيعة النشاط الذي تعمل بـه، حتى تسترشد به في كل القرارات.

r- العملاء: هم المجتمع أو مجموعة الأشخاص والمنظمات الذين يمتلون المستفيدين الحاليين والمرتقبين لما يقدم من سلع وخدمات. r- السوق: تحديد السوق هو بالتالي تحديد لحلبة المنافسـة الذي علينا أن

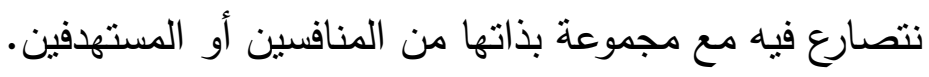
ع- إدراك الإمكانيات: المهم هو إدراك ما يمكن أن نعتمد عليه من نقاط قوة تساعدنا في الفوز وتحقيق الأهداف.

ه- التكنولوجيا: يجب تحديد المستوى التكنولوجي الذي سوف يعتمد عليه، وذللك في إطار التكلفة والعائد والجودة.

7- مجال النشاط والنمو : المنطقة الجغرافية التي يشملها النشاط. V- الإطسار الأخلاقي: والإطسار الأخلاقي يبين الالتزام الأدبي نحو البيئة والمجتمع المحلي والمجتمع العالمي والإنساني عمومًا.

\section{مواصفات مضمون بيان الرسالة}

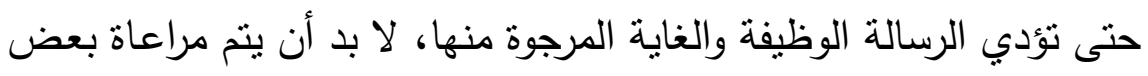

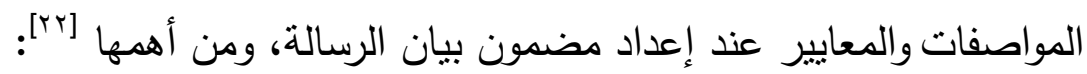


1- يحـد الغايـة مـن الوجـود: إن فهم الغايـة والتعـرف عليهـا مهم جدًا

للقرارات التي يتم اتخاذها، وبدون وجود الغاية سيواجه الإقليم أو الدولة أو المؤسسة بعض العقبات والصعوبات في نشر نشاطاتها والتعربف بها.

r- يصف آليات العمل: يجب أن يوضـح مضمون بيـان الرسـالة كيف

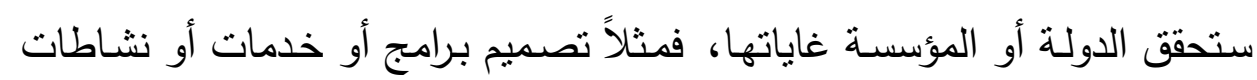
هي من آليات العمل التي يتم اتباعها لتحقيق الغايات .

r- يحدد الفئات المستهفة: يجب تحيد الفئات المستهفة بحسب الغايات المرجوة. ع- يصـف القيم: المجتمـع يهتخ بـالقيم التـي تتطلاق منهـا المنظمـة في تقديم خدماتها للفئات التي تستهدفه، وقد تكون هذه القيم دينية أو إنسانية أو فكرية... إلخ. ه- مضمون مركزز ومختصر وواضـح: إن تركيز مضدون بيان الرسالة وجعله محصورًا في جوانب واضحة يساعد في تكوين صورة واضحة عنها لدى المجتمع، والاختصسار في مضمون الرسالة يساعد المجتمع على سهولة حفظه أو تذكره. ولا بد أن تتم صياغة بيان الرسالة بلغة واضحة وبسيطة ولا تحتمل التأوبل

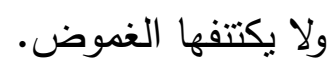

ونظرًا لخصوصية مضموني الرؤية والرسالة، فإنهما تمثنان "البوصلة" لكافة الجهود والنشاطات والتوجهات. فالأهداف يجب أن تعبر عن الرسـالة، والخطـة

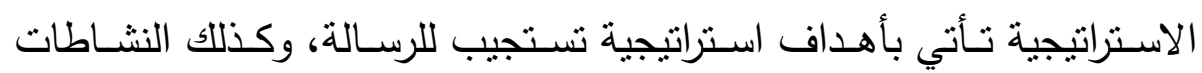
والخدمات يؤدي تطبيقها إلى إحداث آثار وتغييرات في المجتمع تجد صداها في الرسالة. فأي شيء نقوم بـه يجب أن يؤدي بالضرورة إلى تحقيق الرسالة وبالتالي

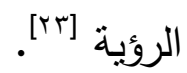

ومن الأخطاء الثائعة، اعتبار أن الرؤية والرسالة ثابتتان لا يمكن تغييرهما

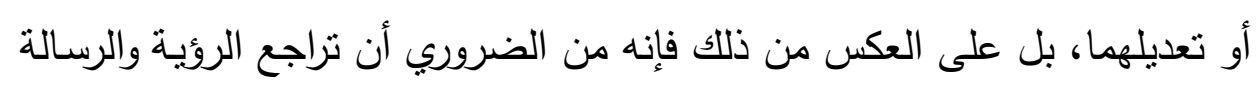


دوريَّا وكلما اقتضت الحاجة ذلك، وأن يتم تعديلهما أو تغييرهما إذا ما طرأت أمور مستجدة عليهما. غير أنه تجدر الإثارة إلى أن الرؤية، وبحكم طبيعتها المستقبلية،

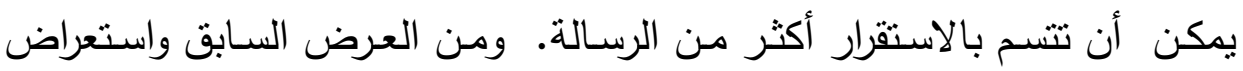
المواصفات لمضمون الرسـالة فإنـه يمكن اعتبار مثال الرسـالة في موضوع بحثنا كما يلي:

"تحقبق مجتمع عربي رائد ومنافس في الخدمات والعلوم والبحوث الطبية، والمساهمة في النطورات الطبية العالمية، وتنهية الموارد العلمبية والتندبيية والخدمبة، عبر النظرة الثاملة والتخطبط المتكامل والتنسبق والتعاون ". يوضـح الشكل (r) كيف تمت مراعاة المواصفات والمعايير المذكورة عند إعداد مضـمون بيـان الرسـالة، حيـث تم تحديد الغايـة مـن التخطبط الاستراتيجي للعمل الطبى العربى المشترك، وتم وصف آليات العمل للوصول للغاية المرجوة، كما تم تحديد الفئات المستهدفة، ثم تم وصف القيم التي تتطلق منها مجموعـة الدول، وكل ذللك في مضدون مركَز ومختصر وواضح.

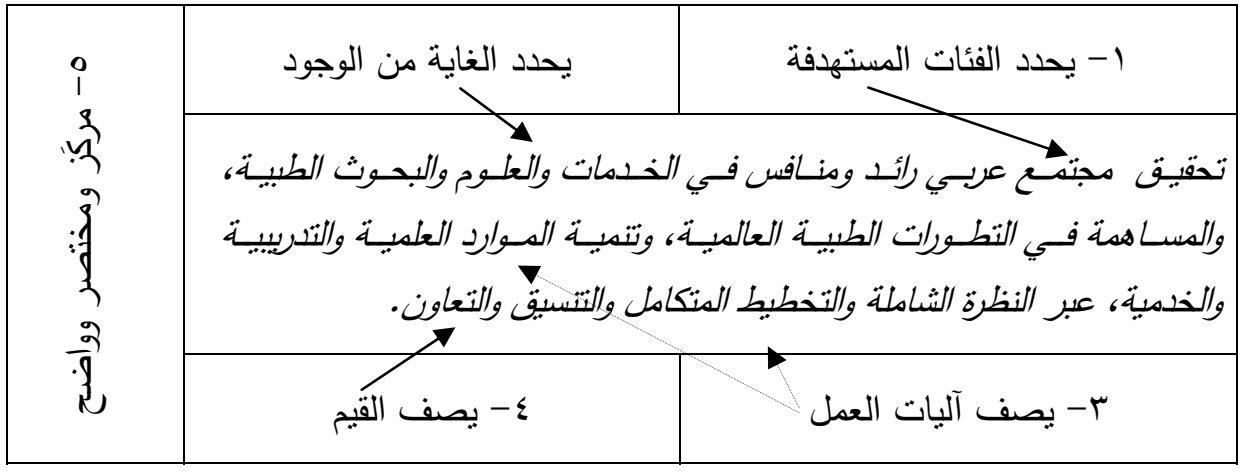

شكل (ץ). مراعاة المواصفات والمعايير عند إعداد مضمون بيان الرسالة. القبم القيم هي الأخلاقيات التي تحكم تصـرفات المنظمـة أو الجماعـة أو الجهة

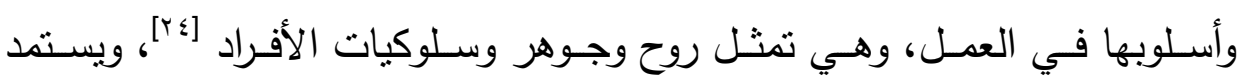


المجتــع العربـي قيمـهـ مـن المبـادئ السـامية للأديـان السـماوية التى تحض على مكارم الأخلاق، ويستمدها أيضًا من القيم والتقاليد العربية الأصيلة وغير ذلك من مكارم الأخلاق والتي تضفي السعادة والرضـا والقناعة على النفس، وتغذّي النفس بالقيم الروحيّة السامية كما يتغّذى الجسد بالأشياء الحسية، وبالنالي تدفع المجتمع

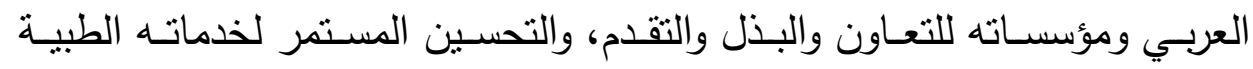
والارتقاء بها وصـولا للمسـاهمة في التقدم العـالمي. وبظهر في الجدول رقم تلخيص لما يمكن أن نعتبره قيمنا الأساسية بالنسبة للعمل الطبي العربي المشترك: جدول (1). القيم التى يمثلها العمل الطبي العربي المشترك.

\begin{tabular}{|c|c|c|c|c|c|c|}
\hline الثمولية & الريادة & التقدام & الإيجابية & التكامل & التتسيق & التعاون \\
\hline
\end{tabular}

- - - - آلأهداف الاستراتيجية العامة

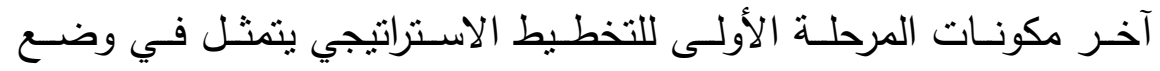
الأهداف الاسـتراتيجية العامـة وهـى الغايـات (الأهداف) التي نستطيع أن نصفها

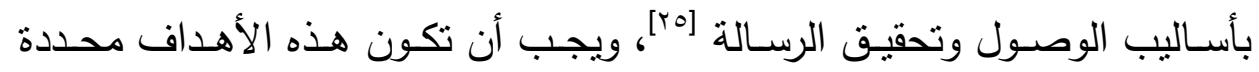
وواضحة للعمل الطبي العربي المشترك وهي:

1- غرس القيم والمبادئ التي تعزز روح الانتمـاء للعروبـة كوعـاء يضـ الأقطار العربية جميعها. r- تحقيق مجتمع عربي قادر وصحيح ومعافى. ب- ترسيخ مفهوم التعاون والمشاركة بين أفراد العمل الطبي ومؤسساته عبر الوطن العربي. ع - إثناعة روح الثقة بين مؤسسات العمل الطبي عبر الوطن العربي. ه- غرس الرغبة في التفوق والمساهمة في التقدم العلمي الطبي العالمي. 
7- العمل على تطوير القدرات العربية في تقديم خدمات طبية عالية وآمنة

ومتميزة.

V- ترسيخ مبدأ الإحساس بالمسؤولية تجاه صحة المواطن العربي والحفاظ على عافيته وسلامته.

\section{צ-r التطليل البئي (SWOT Analysis)}

كلمـة SWOT اختصـار لأربـع مفردات هي: نقاط القوة Strengths، نقاط الضعف Weaknesses، الفرص Opportunities، التهديدات Threats. ويبدأ نطبيق معردي هذا التحليل، باستخدام أسلوب العصف الذهني لمجموعة مختارة من المهتمين وذوي العلاقـة بـالتخطيط لقضية مـا. ومـن ثم يـتم تحديد البيئة الداخليـة والبيئة الخارجية، حيث إن البيئة الداخلية تتمنل في نقاط القوة ونقاط الضعف، بينما البيئة الخارجية تتمنل في الفرص والتهديدات [بr]، التهبه - -

\section{مقومات العمل الطبي العربي المشترك}

بالإضـافة إلى الإيمـان بالعمـل العربي المشـترك، يوجد فـى الوطن العربي

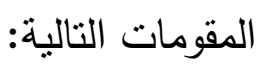

$$
\begin{aligned}
& \text { وحدة الإقليم الجغرافي. } \\
& \text { وحدة الإقليم المناخي. } \\
& \text { وحدة العرق. } \\
& \text { وحدة العادات والتقاليد. } \\
& \text { وحدة اللغة والمصطلحات. } \\
& \text { وحدة التحديات والتطلعات. }
\end{aligned}
$$




$$
\text { معوقات العمل الطبي العربي المشترك معنى القليطى و إيرهيم عبد العزيز الضراب }
$$

\section{معوقات الععل الطبي العربي المشترك}

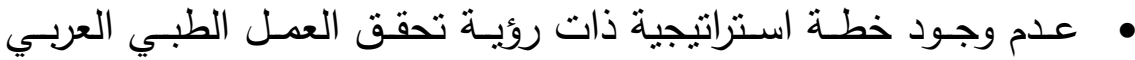

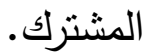

اختلاف القوانين والنظم الصحية.

عدم استكمال الهياكل والمنظمات الصحية العربية الموحدة.

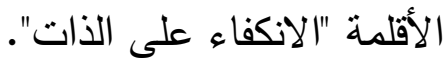

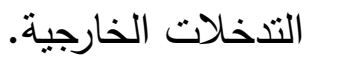

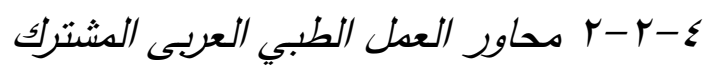

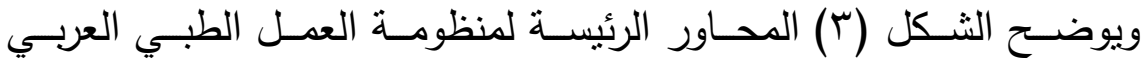

المشترك. وترتكز منظومـة العمل الطبي العربي على قوائم متعددة، والتي تمثل محاور أو عناصر البيئة الداخلية، والتي يمكن إجمالها في النالي:

1- مؤسسـات التعليم والتـدريب والبحث مثنل الجامعـات والمراكز البحثيـة

العلمية والطبية المتخصصة.

r- الأطقم الطبية المختلفة العاملة بالحقل الطبي (كوادر الحقل الطبي).

r- المؤسسات الطبية من مراكز صحية ومستشفيات عامة ومتخصصة.

ع - مؤسسات الاعتماد والتسجيل والتصنيف وضمان الجودة للأطقم الطبية

وللمؤسسات الطبية المختلفة.

0- ركائز صناعة الدواء (مراكز البحث، رؤوس الأموال، السوق).

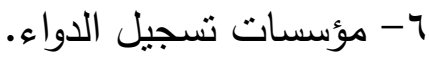

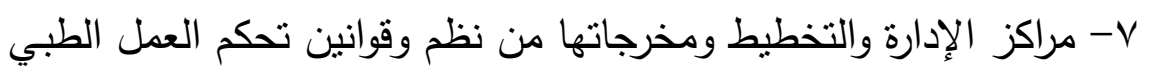

ومن ورائها تتريعات الدولة وتوجيهات الحكومات والنظم.

1- وسائل الإعلام والتوعية والتثقيف الصحي. 


$$
\text { 9- شبكة اتصالات طبية عبر الوطن العربي. }
$$

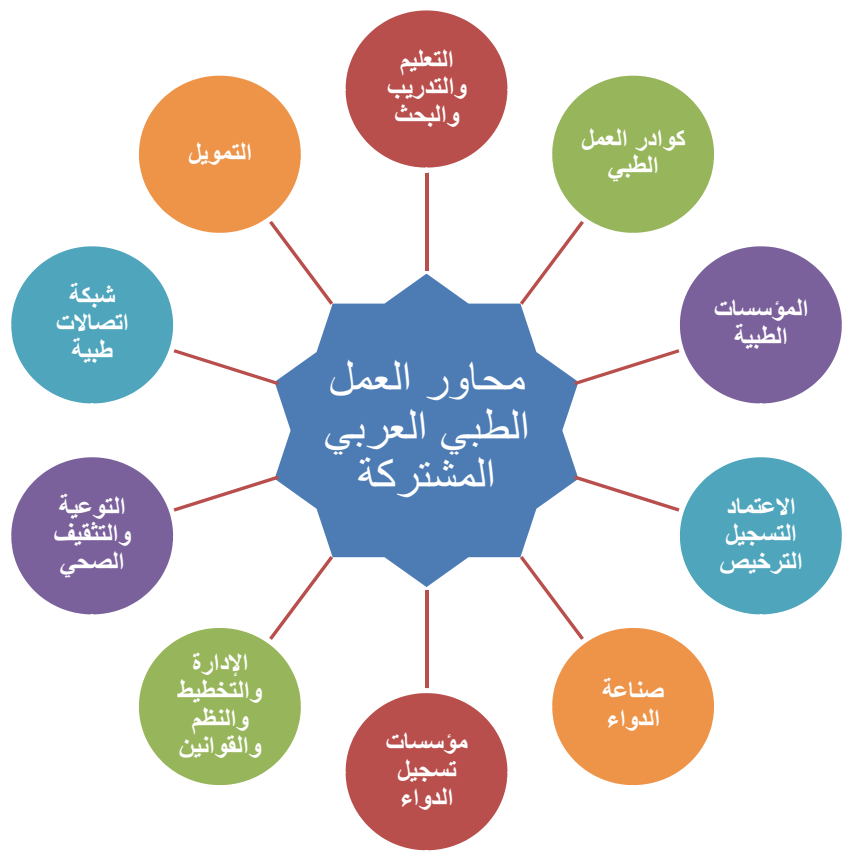

شكل (ץ). المحاور الرئيسة لمنظومة العمل العربي الطبي المشترك فى البيئة الداخلية. ويوضح الجدول (Y) عناصر القوة والضعف فى البيئة الداخلية.

\begin{tabular}{|c|c|c|}
\hline نقاط الضعف (Weaknesses) & نقاط القوة (Strengths) & المحاور الرئيسة \\
\hline 1- عدم وجود خطة لتكامل التعليم والتدريب & 1- وجود الكفاءات العلمية. & ا ا. المؤسسات الطبية \\
\hline والبحث. & r إنشــــاء المجلــس العربـــي & للتعليم والتدريب \\
\hline ץ- قلّــة البحــوث العلميـة في مجــال ربـــ & ل للتخصصات الطبية. & والبحث \\
\hline التعليم بواقع المجتمعات العربية ومشكلاتها & ب- تــــفر المــدارس والمعاهــــ & \\
\hline 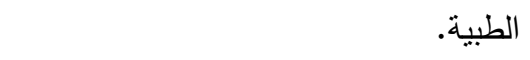 & والجامعـات والجمعيـات الطبيـة & \\
\hline 1 - محدوديــة النـدوات والمحاضـرات التـي & المعنيــــة بـــالتعليم والتـــدريب & \\
\hline تعنى بالتعاون الطبي العربي. & والبحث في المجال الطبي. & \\
\hline ع - الفجوة العلمية والتكنولوجية والتدريبية. & & \\
\hline
\end{tabular}

جدول (r). عناصر القوة والضعف فى البيئة الداخلية. 


\begin{tabular}{|c|c|c|}
\hline نقاط الضعف (Weaknesses) & نقاط القوة (Strengths) & المحاور الرئيسة \\
\hline 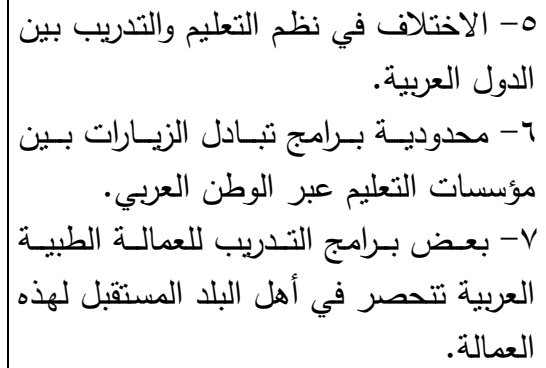 & & \\
\hline 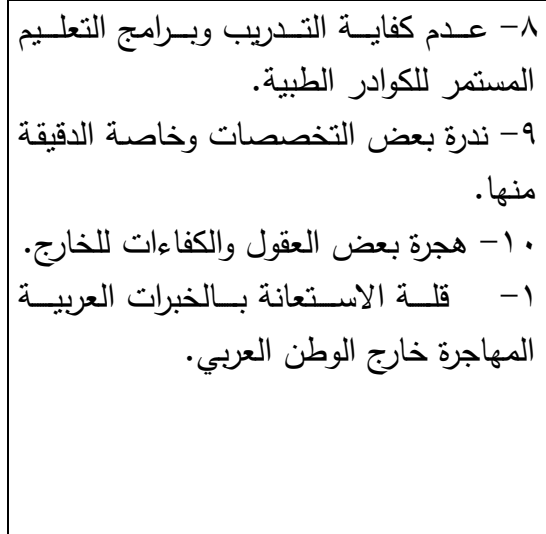 & 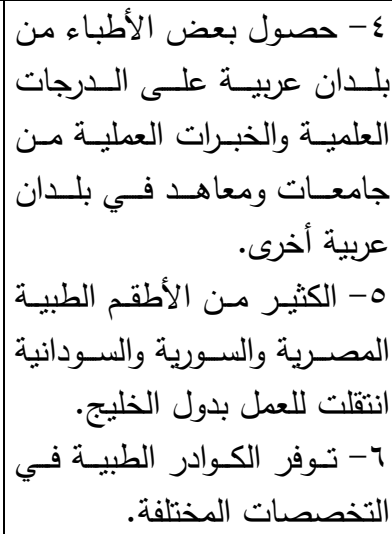 & rالطبية الأطقم والكوادر \\
\hline 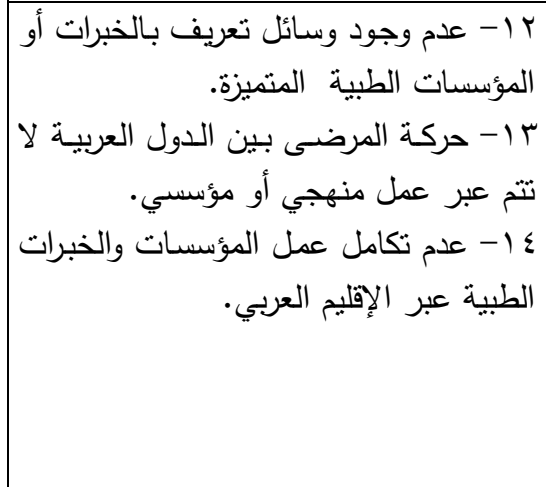 & 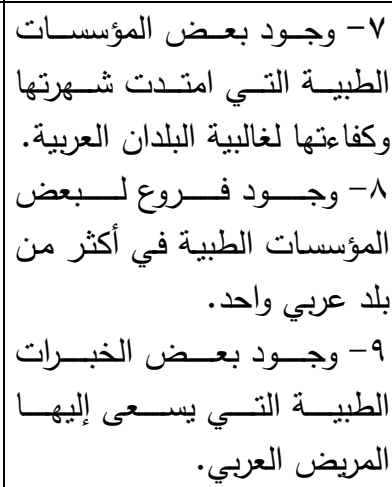 & r- المؤسسات الطبية \\
\hline 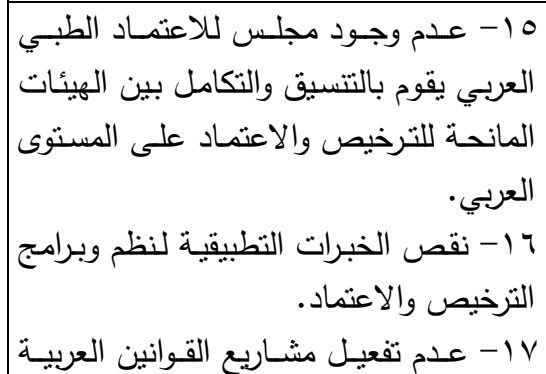 & 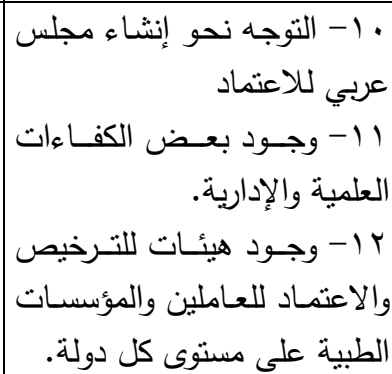 & و و التسجيل والتصنسات الاعتماد \\
\hline
\end{tabular}




\begin{tabular}{|c|c|c|}
\hline نقاط الضعف (Weaknesses) & ths) نقاط القوة & ل اور الرئيسة \\
\hline والبيطري ومهنـة لمزاولـة الصيدلة. مهنــة الطـب البشــري & & \\
\hline 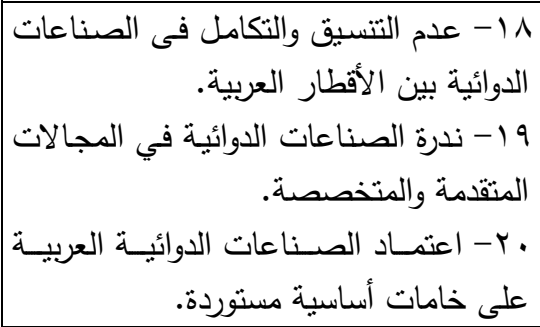 & 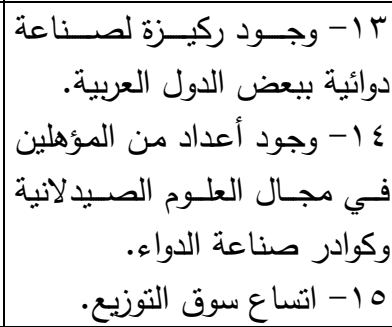 & 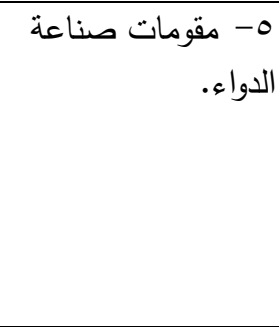 \\
\hline 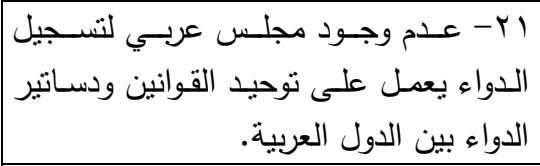 & 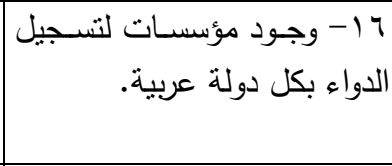 & $\begin{array}{r}\text { الدواء - مؤسسات تسجيل } \\
\text { الدواء }\end{array}$ \\
\hline 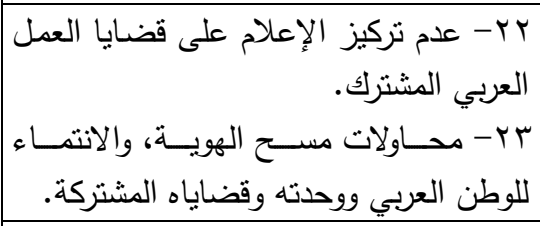 & والعادات والتقاليد. & والتيقيف الصحئل الإعلام \\
\hline 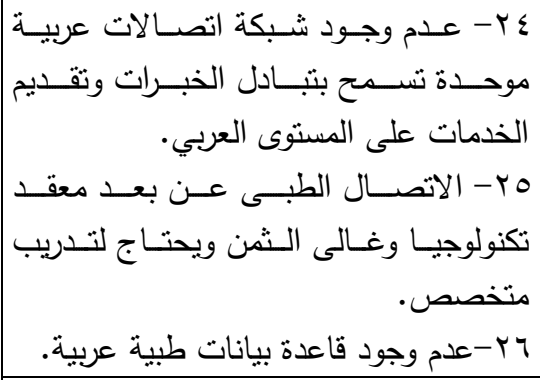 & 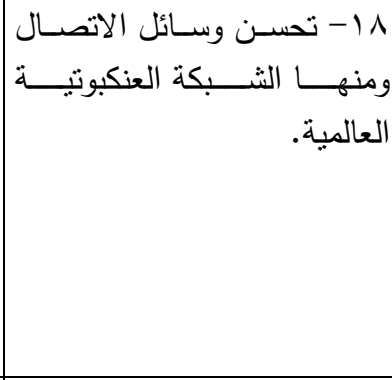 & بين البلدان العربية. الاتصات الطبية \\
\hline 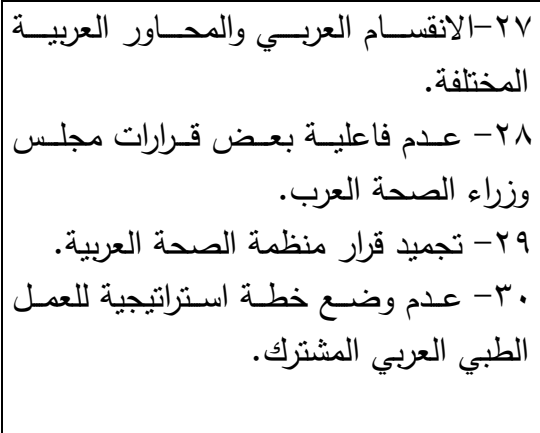 & 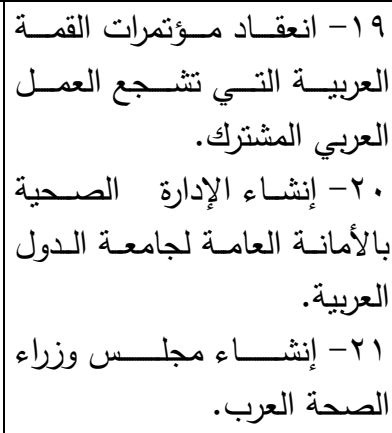 & 9- الإدارة والتخطبط \\
\hline العربية للخدمات الصحّهـه مـن ميزانيـات بعض أقل من المطلوب. & 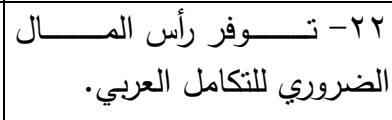 & • 1 - التمويل \\
\hline
\end{tabular}


-

يمثّل الجدول (ب) الفرص والتحديّات الرئيسية التي تواجه المجتمع كتحليل

للبيئة الخارجية والظروف العالمية المحيطة.

جدول (r). تحليل البيئة الخارجية (الفرص والتحديات).

\begin{tabular}{|c|c|}
\hline $\begin{array}{r}\text { التصديات } \\
\text { (Threats) }\end{array}$ & $\begin{array}{c}\text { الفرص } \\
\text { (Opportunities) }\end{array}$ \\
\hline 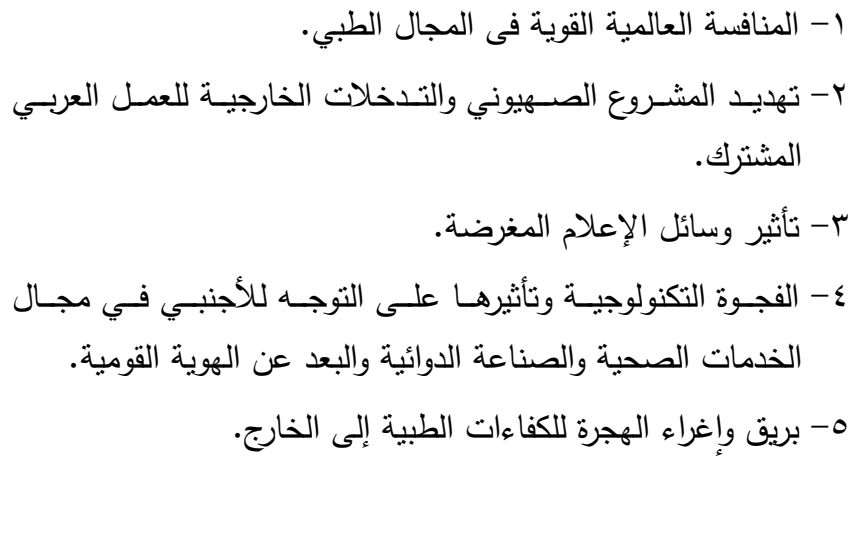 & 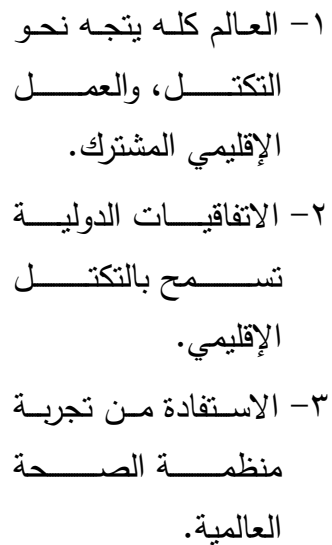 \\
\hline
\end{tabular}

\section{צ-}

يمكـن اسـتباط البـرامج التتفيذيـة المطلوبـة لتحقيـق العمـل الطبـي العربـي المشترك وذلك باتخـاذ الإجراءات المناسبة لتفادي نقاط الضـف والاسـفادة من نقاط القوة في البيئة الداخلية، وكذلك لمواجهة التحديات وانتهاز الفرص في البيئة الخارجية. ويوضـح الجدول (ع) البرامج التتفيذية المقترحة وعلاقتها بنقاط القوة Opportunities وكذا الفرص Weaknesses (W) ونقاط الضعفStrengths (S) .Threats (T) والتحديات (O)

ويقترح الباحثنان إنشـاء منظمـة للصحة العربيـة تكون مهامها وضـع وتتفيذ ومتابعة البرامج المقترحة. 


\section{جدول (؛). البرامج التنفيذية وعلاقتها بنقاط القوة والضعف في البيئة الداخلية.}

\begin{tabular}{|c|c|c|c|c|}
\hline البرامج التنفيذية المقترحة & $\underline{E}$ & E. & ह. & $\underline{\underline{E}}_{=}^{:} \frac{b}{E !}$ \\
\hline 1- برنامج تكامل التعليم والتدريب والبحث على مستوى البلدان & & & $\begin{array}{l}1.260 \\
7, V\end{array}$ & $\begin{array}{lll}16 \\
16\end{array}$ \\
\hline 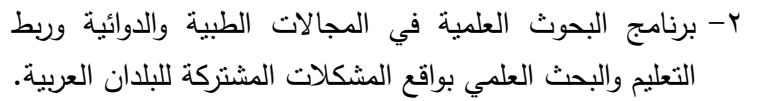 & $\varepsilon$ ، & r & $96 r$ & r \\
\hline 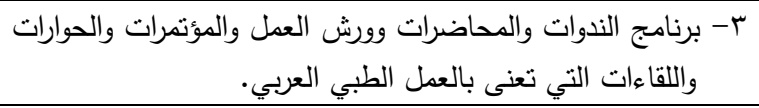 & r & & r & IV \\
\hline 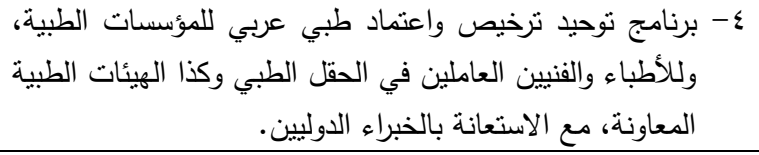 & & 1 & $\begin{array}{l}1710 \\
18\end{array}$ & $\begin{array}{l}111 . \\
11814\end{array}$ \\
\hline 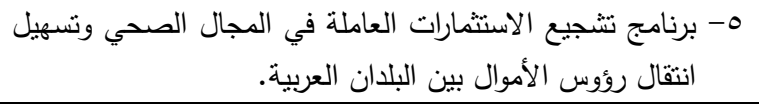 & & r.l & M & TY IV \\
\hline 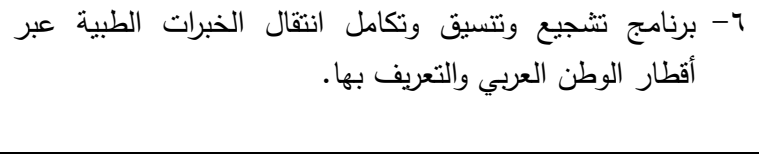 & 1 & & $\begin{array}{l}\text { is } \\
\text { it }\end{array}$ & $\begin{array}{l}626061 \\
676 \mathrm{~V} \\
I V_{6} \wedge\end{array}$ \\
\hline V- برنامج نشجيع وتتسيق انتقال المرضى للعلاج عبر أقطار & 1 & & & $\begin{array}{l}V_{6} \wedge 0.7 \\
961 V\end{array}$ \\
\hline 1- برنامج خلق كيانات كبرى في صناعة الدواء وإجراء البحوث & $r .1$ & r.l & $\begin{array}{l}1911 \\
r .\end{array}$ & $\begin{array}{l}1 \leqslant 14 \\
10\end{array}$ \\
\hline 9- إنشاء مجلس تسجيل ومراقبة موحد للدواء العربي. & & & Y) & 17 \\
\hline 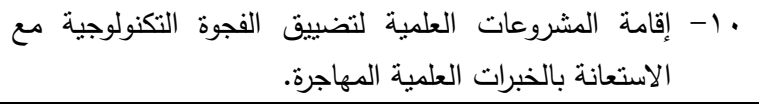 & $\begin{array}{l}1, r \\
0, \varepsilon\end{array}$ & & $96 \varepsilon$ & r. \\
\hline 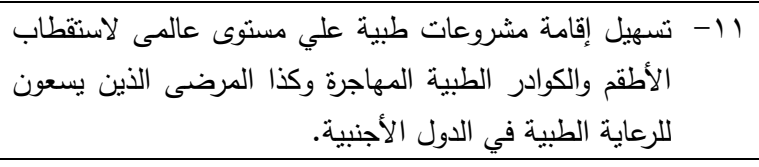 & 0.1 & r. & 1.69 & $\begin{array}{rll} \\
\end{array}$ \\
\hline 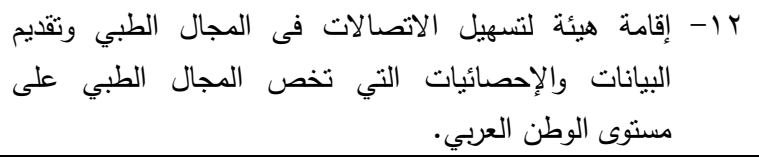 & & & $\begin{array}{l}\text { rs } \\
\text { ro } \\
\text { ry }\end{array}$ & 11 \\
\hline 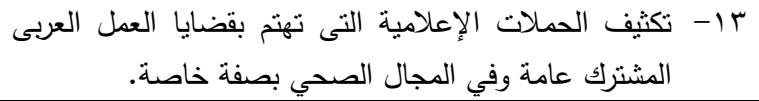 & r & & $\begin{array}{l}r t r \\
r\end{array}$ & $\begin{array}{l}611.61 V \\
Y 1, r \cdot 619\end{array}$ \\
\hline
\end{tabular}

الأرقام داخل الأعمدة الأربعة الأولي تمثل الأرقام المسلسلة لنقاط القوة والضعف والفرص والتحديات على التوالي والمذكورة في الجدولين (rو بام). 


\section{التعريف بنظمة الصحة العربية المقترحة}

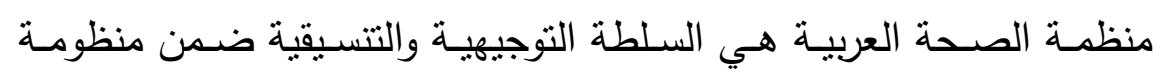
العمل العربي المشترك فيما يخص المجال الصحي، وهي مسؤولة عن تأدية دور قيادي في التخطيط وفي معالجة المسائل الصحية العربية، وكذا تصميم البرامج وهيج التعليميـة والتدريبيـة والبحثيـة في المجـالات الصـحية، ووضـع القواعد والمعـايير للاعتمـاد والتشــيل والتصـنيف وضـمان الجـودة في المجـال الطبـي، وتوضـيح الخيارات السياسية المؤيدة بالبيّنات في النواحي الصـحية، وتوفير الدعم التقني للبلدان العربية، ورصد الاتجاهات الصحية وتقييمها، ووضـع سياسـات الأدوبـة بلية والمستحضرات الصبدلانية الأساسية، ونشر الوعي والثقافة الصحية. وردات

\section{المهام الرئبية لمنظمة الصحة العربية}

ا. العمل على تكامل التعليم والتدريب والبحث على مستوى البلدان العربية. r. تشـجيع البحوث العلميـة في المجـالات الطبيـة والدوائيـة وربط التعليم والبحث العلمى بواقع المشكلات المشتركة للبلدان العربية.

r. تشجيع عقد الندوات والمحاضرات وورش العمل والمؤتمرات والحوارات واللقاءات التى تعنى بالعمل الطبي العربي.

ـ. تـرخيص واعتمـاد طبـي عربـي موحـد للمؤسسـات الطبيـة، وللأطبـاء والفنيين العاملين في الحقل الطبي وكذا الهيئات الطبية المعاونة. ه. توحيد الأنظمة الصحية المطبقة بكامل المنطقة العربية. 7. تسهيل انتقال رؤوس الأموال والاستثمارات العاملة في المجال الصحي. V. تسهيل انتقال الخبرات الطبية عبر أقطار الوطن العربي. ^. تسهيل انتقال المرضى للعلاج عبر أقطار الوطن العربي. 
9. تعزيز شركات الدواء العاملة في العالم العربي لخلق كيانات كبرى في

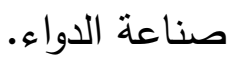

• 1 . إنشاء مجلس تسجيل ومراقبة موحد للدواء العربي. 11. الارتقـاء بالوضـع الصـحي للمـواطن العربي مـع الاسـتفادة والتتسـيق والتعاون مع المشروعات القائمة.

r ا. ـ تشجيع إقامة المشروعات العلمية لتضييق الفجوة التكنولوجية. rا ـ تشيع إقامة مشروعات طبية ذات مستوى عالمي لاستقطاب الأطقم

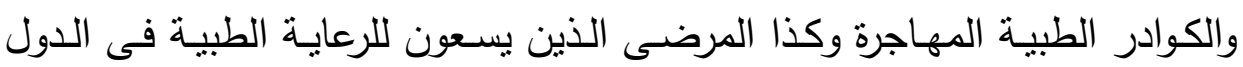
الأجنبية.

ع ا . إقامـة شبكة اتصـالات للخدمات الصـية وتقديم مـا بلزم من بيانات وإحصائيات تخص المجال الطبي على مستوى الوطن العربي. 1 . . تكثيف الحملات الإعلامية التى تهتم بقضايا العمل العربي المشترك عامة وفى المجال الصحي بصفة خاصة. الهيكل التنظيسي المقترح للمنظمة يوضــح الثــكل (ع) الهيكـل التنظيمسي المقتـرح لمنظمــة الصــحة العربيـة ويتضمن الهيئات والأمانات والأجهزة والمراكز والإدارات المختلفة بالمنظمة. وفيما

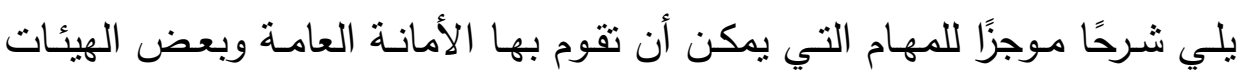
والأمانات والأجهزة والمراكز المختلفة بالمنظمة:

- - الأمانـة العامـة للمنظمـة: وتضم الأمين العام، السكرتارية العامـة، إدارة

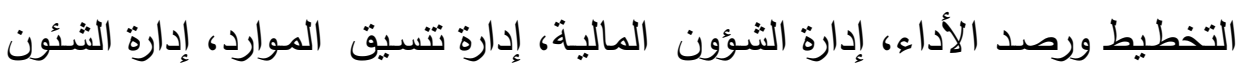
القانونية، وإدارة الأزمات والكوارث. 
- - إدارة الأزمات والكوارث: وتهتم بعمليات الطوارئ والمهمات الخاصة، بناء القدرات، الإنذار بحدوث الأوبئة والاجتياحات المرضية ومواجهتها، وكذا الاهتمام بالأمن العربي في مواجهة الحروب البكتيرية والبيولوجية المحتملة.

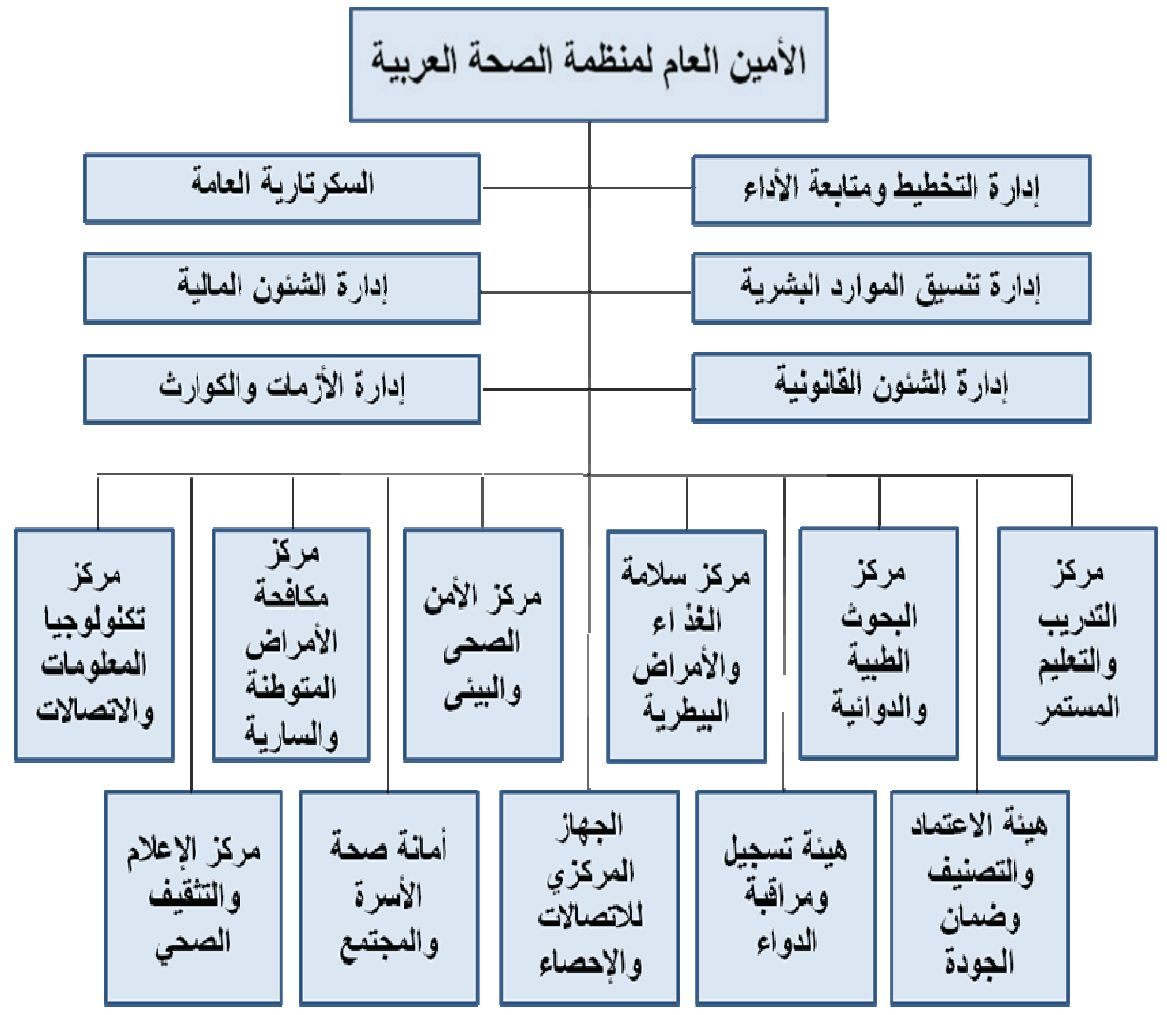

شكل (؛). الهيكل التنظيمي المقترح لمنظمة الصحة العربية.

- هيئة الاعتماد والتصنيف وضمان الجودة: وتهنم باعتماد وتصنيف وتسجيل الكوادر الطبية والمؤسسات الطبية العاملة عبر الوطن العربي، وضع سياسات وإجراءات الخدمات الصحية، وجودة النظم الصحية وتقديم الخدمات. - هيئة تسجيل ومراقبة الدواء: وتهتم بوضع سياسات ودساتير الأدوبة والمستحضرات الصيد لانية، ومراقبة الأدوية ونأثيراتها الجانبية. 
- أمانة صحة الأسرة والمجتمع: وتهتم بصحة الأطفال والمراهقين ونموهم، التطعيم واللقاح والمستحضرات البيولوجية، الصحة الإنجابية وبحوثها، والرعاية الصحية للمسنين.

- مركز الأمن الصحي والبيئة: وبهتم بحماية البيئة العربية والوقاية ضد العنف والإيذاء الجسدي، الوقاية من الإصابات والعجز ، الصحة النفسية وعلاج الإدمان، والعمل على الإقلاع عن التذخين.. - مركز سلامة الغذاء والأمراض الحيوانية: ويهتم بالبحث عن المصدر والأمراض المنقولة بالأغذية، والأمراض المنقولة عبر الحيوانات، والتغذية من أجل الصحة والتتمية.

- مركز مكافحة الأمراض المتوطنة والسارية: ويهتم بمكافحة الأمراض المتوطنة وأمراض المناطق الحارة، ومكافحة الملاريا، واستئصال شلل الأطفال، ومكافحة الإيدز، ودحر مرض السل، وعلاج الأمراض المزمنة وتعزيز الصحة، ومكافحة انتثار العدوى.

\section{ع - ح وضع الغطط التشغيلية المرحلية}

تكمن أهمية هذه المرحلة في أنها تمكّن من وضع تفاصيل النشاطات ضمن تسلسل متتاغم ومنطقي، يعتمد بالأسـاس على ترتيب أولويات هذه النشاطات من

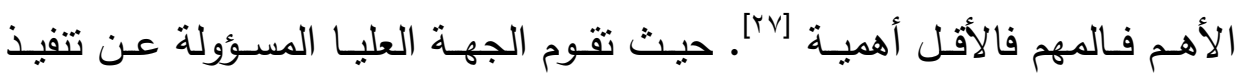
الاستراتيجية (منظمة الصحة العربية) وبمشاركة كل الجهات التتفيذية وبالتعاون مع المتخصصين بوضـع تفاصيل دقيقة للبرامج التفيذية، ويمكن في هذه المرحلة أن تثبلور عدة برامج تتفيذية لكل عنوان واحد حتى بتم تحقيقه على الوجه الأكمل. 
وتتضمن التفاصيل الدقيقة للبرامج التنفيذيـة ما يلي: المحور الاستراتيجي،

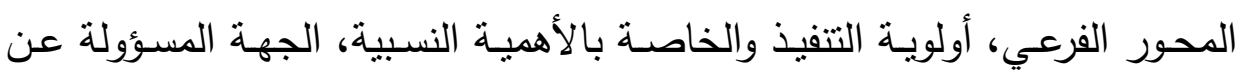
التتفيذ، الجهات ذات العلاقة، الخطوات التتفيذيـة، الموارد المطلوبة، الفترة الزمنية لتتفيذ كل خطوة، الوقت المقترح لبدء البرنـامج، مخطط جانـت لتوقيتات التتفيذ، المـدة الإجماليـة لتتفــذ البرنـامج، التكلفـة الإجماليـة، مؤشـرات الأداء ومؤثـرات الإنجاز ، ومحددات ضمان الجودة [^ז]. ومخطط جانت هو نوع من الرسوم البيانية الثـائعة على شكل تخطيط شريطي يوضتح الجدول الزمني لتنفيذ المشروع، حيث

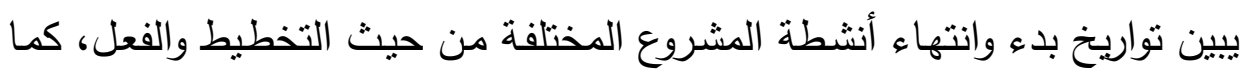
يظهر أيضا العلاقات النسبية بين الأنشطة.

\section{ك - - توثيق وتداول الخطة}

وهى المرحلة التي يتم فيها نوثيق أعمال عملية التخطيط وذلك من خلال

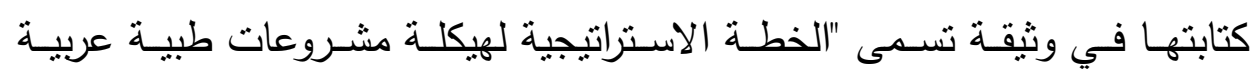
مشتركة"، ويجب كتابـة الخطة بطريقة منهجيـة وواضحة ومحدّدة، وبجب الاهتمام بمستوى التظيم والطباعة والمظهر وكلها من الأشياء الهامة حتى وإن كانت شكلية أو مظهرية، وتحتوي "وثثقة" الخطة على مشتملات رئيسة لا بـ من توفرها، وهي ولهي

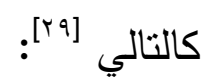

• الملخص التتفيذي: وهو فقرة تتضمن تلخيصا للخطة. • إجراءات التخطيط: وتضم مراحل التخطيط، من يشارك في التخطيط، المعلومات ومصادرها، الوقت الذي استغرقته عملية التخطيط ... إلخ. • الأطر الاستراتيجية: الرؤية، الرسالة، القيم والأهداف. • التوقّعات: يتم ذكر النتائج التي من المتوقع الوصول إليها. • فريق العمل: ذكر المعنبين بهذه الخطة. 
• الموازنة التقديرية والمدة.

وبعد كتابة الخطة وتدقيقها واعتمادها، يجب الإعلان عنها وتوفيرها للجهات ذات العلاقة وكذا لمـن يطلبها مـن الجهات المهتمـة، فذلك يكون فهمًا جماعيًا للخطـة وبكون التزامًا بها. فـلا بـد أن تجتهد الدول العربيـة والمنظمـات الإقليميـة القائمة في إيصال خطّتها إلى كل من يساهم في إنجازها، وأن تستخدم عدّة وسائل للتعريف بها وبمضمونها .

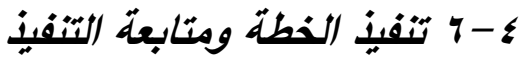

وهي من أكثر المراحل دقّة، فكما هو ملاحظ بأن الخطة العامة تحتوي على "نشاطات رئيسة" إن لم يتم وضعها وترجمتها في خطط عمل فلن يتم تتفيذ الخطة العامة بشكل فعال ودقيق، فيقوم كل طرف معني بدراسـة الجزء الذي يهتم بـه في الخطة العامة ويضع لله خطة عمل نترجمه إلى نشاطات فرعية وتحديد الإجراءات الازم اتخاذها لتنفيذ كل نشاط فرعي، والفريق المسؤول عن تتفيذه والمدة الزمنية المتاحة لتنفيذه والموارد التي يحتاجها الفربق لتتفيذه [•r"] التغذية العكسية ومراجعة الإطار الاستراتيجي Vوهي المرحلة الأخيرة من مراحل التخطيط، وهى مرحلة مستمرة ومتكررة، وتتمثل في استخدام نتائج مرحلة تحديد الواقع ومطابقتها مـع الإطلار الاستراتيجي بهدف التعرف على مدى استجابتها وانسجام الواقع مع أطرها الاستراتيجية. وتحديد الأمور التي بحاجـة إلى جهد واهتمـام وتركيز للوصسول إلى تحقيق كامل الأطر الاستراتيجية. كما تساعد هذه المرحلة في التعرف على التعديلات الـازم إدخالها

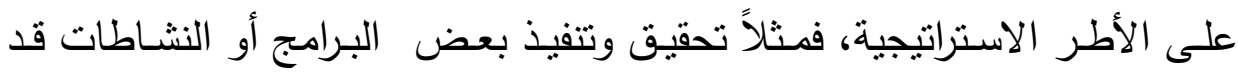
يقضي إجراء بعض التعديلات على الرسالة والخطة الاستراتيجية، ومن ثم إجراء 
تحليل بسمى "تحليل الفجوة "وهو تحليل بستخدم للتعرف على الفجوة الفاصلة بين الواقع الحالي وبين التصور للمستقبل، للعمل على سد هذه الفجوة [اr].

\section{0- الخلاصة}

ا- تم مراجعـة خطوات التخطيط الاستراتيجي بمراحلـه المختلفة: المرحلـة الأولى، وهي تحديد المفاهيم الأساسية لعملية التخطيط وهي الرؤية والرسالة والقيم

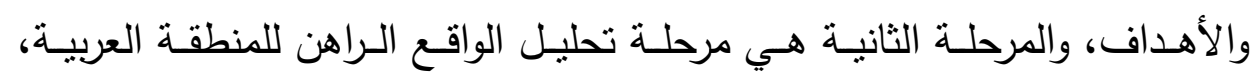

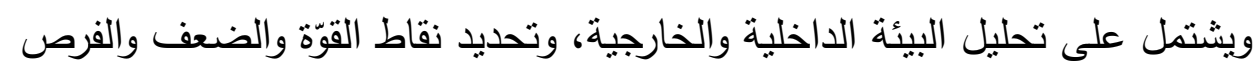

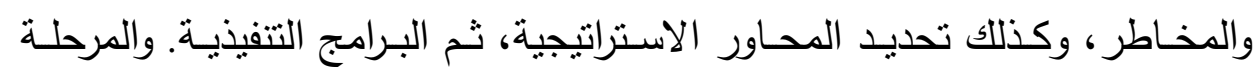

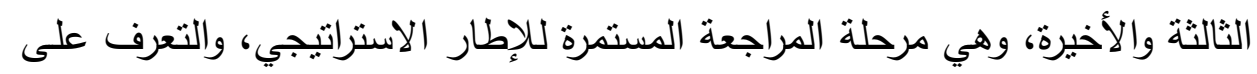
التعديلات اللزم إدخالها على الأطر الاستراتيجية طبقا لواقع التطبيق العملي. r- تم تحديد الإطار الاستراتيجي لتحقيق مشروعات طبية عربية مشتركة ويشتمل على: الروئية والرسالة والقيم والأهداف الاستراتيجية العامة.

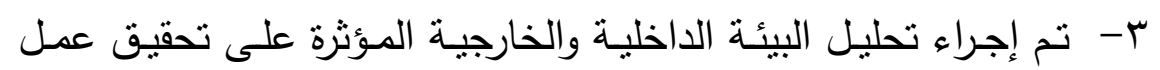

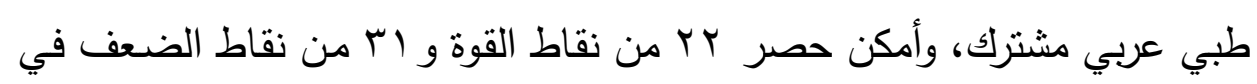

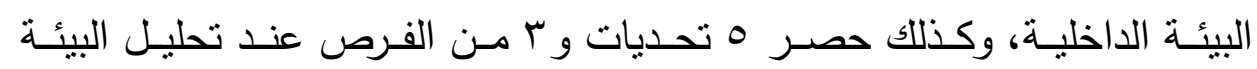

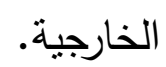

ع- تم اقتراح إنثاء منظمة للصحة العربية لتحقيق مشروعات طبية عربية

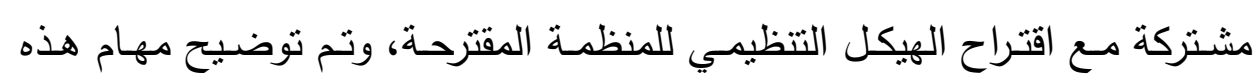
المنظمة ، وهذه المهام تغطي كافة المحاور الرئيسة العشرة المرتبطة بالموضوع. 0- نم اقتراح ب ا برنامجًا تتفيذيًا لتلافي نقاط الضعف ولاستخلال نقاط القوة في البيئة الداخلية، وكذلك لانتهاز الفرص ومواجهة التحديات في البيئة الخارجية، 
rAO

مع توضيح العلاقة بين البرامج المقترحة ونقاط الضعف والقوة والفرص والتحديات

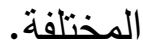

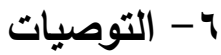

1- ثنبى خطّة استراتيجية لتحقيق تعاون طبي عربي مشترك، ويجب أن تتضافر في تتفيذ هذه الخطة كافة الأقطار العربية ومنظماتها المختلفة التي تعمل فلتحن في الحقل الطبي.

r- تتميـة القوى البشرية التي لها علاقة مباثرة أو غير مباشرة بموضوع العمل الطبي المشترك مثل المؤسسات التعليمية والثقافية ووسائل الإعلام الدقروءة والمرئية والمسموعة، بما يؤهلها لدور رائد في تحقيق العمل الطبي المشترك، حيث الإني

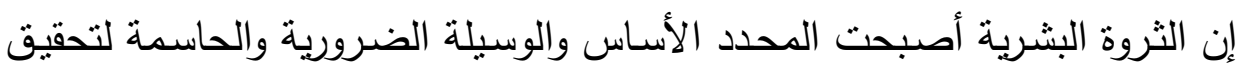
ما نتطلع إليه من الإنجازات على كافة المسنويات.

r- نقوية وتطوير القدرات الوطنية للبحث والتطوير في المجال الطبي، مع ربط جهود البحث والتطوير باحتياجات المجتمعات العربية، مع تبني آليات فاعلة

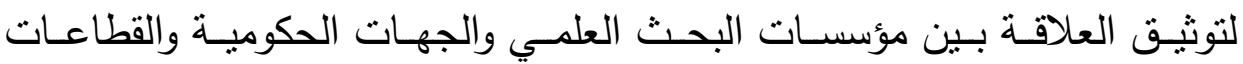
المجتمعية الأخرى، مع الاستفادة من المؤسسات ذات العلاقة والموجودة فعلا متلك: • لجنة الصحة بالأمانة العامة لجامعة الدول العربية.

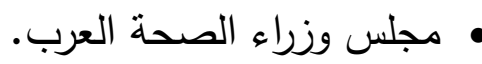
ه المجلس العربي للاختصاصات الطبية.

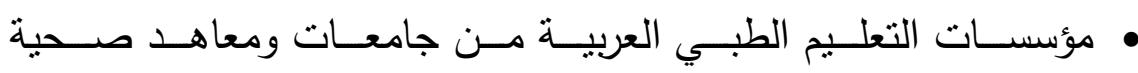
منتشرة عبر الأقطار العربية. • المؤسسات الطبية العربية القائمة. 


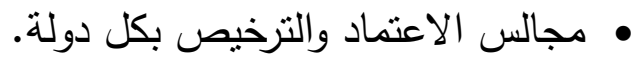

$$
\text { • مجالس التسجيل الدوائي بكل دولة. }
$$

شركات ومعامل الأدوية المنتشرة في البلدان العربية.

ع - الاهتمـام بتوطين وتطوير التقنيـة المتقدمـة في المجـال الطبي: وذلك لتضييق الفجوة التكنولوجيـة والعلميـة وتأثيرها السلبي على تأخر المجتمـع العربي عن التطور العالمي، خاصـة وأن هناك الكثير من العلمـاء والنـابغين في مجـال الخدمات الطبيـة والذين يمكن الاعتمـاد عليهح في تكـوين نـواة لتطـوبر التقنيـة التكنولوجية المتقدمة.

0- إنشـاء منظمـة عربيـة للصحة ملزمـة "لقراراتها قوة القانون" عبر الوطن العربي تقود وتخطط وتتسق وتتفذ العمل الطبي العربي المشترك في كافة المحاور ذات العلاقة.

7- العمل على تبنّي البرامج التفيذية المقترحة لتحقيق العمل الطبي العربي المشترك مع تضافر كافة الجهود الحكومية وغير الحكومية لتتفيذها، مع استخلال نقاط القـوة، وتلافى نقـاط الضـفف في البيئة الداخليـة، وكذللك انتهـاز الفـرص ومواجهة التحديات في البيئة الخارجية.

\section{شكر وعرقان}

يهذي الباحثان نتائج هذا البحث إلى روح الطبيب "جمال على حسن حسن" (رحمه الله)، والذي ظل مهتما طوال حياته بالموضوعات الوطنية بالعالم العربي.

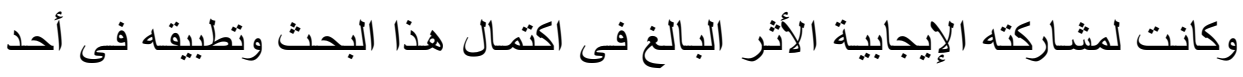
المجـالات الهامـة وهـو المجـال الطبىى على مسـتوى العـالم العربـي. ونـدعوا الله سبحانه وتعالى أن يجعل نتائج البحث في ميزان حسناته. 


\section{المراجع}

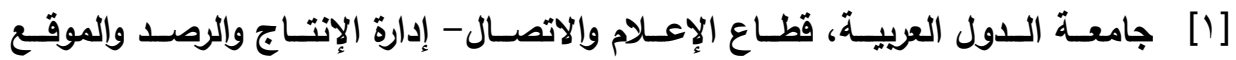

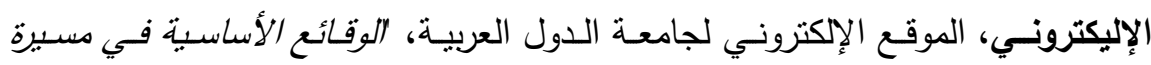

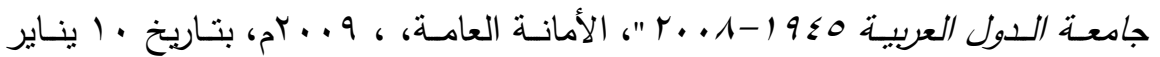
http://www.arableagueonline.org/las/arabic/search_ar.jsp : جمعه، أحمد محمود، إنشاء جامعة الدول العربية- مقدماتها وتطورها ، الهيئة المصرية

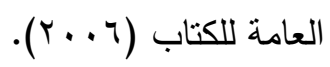

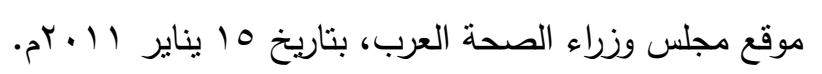
http://www.acmls.org/Council/Council.htm

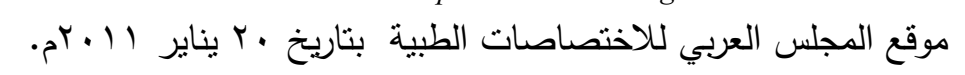
http://www.cabms.org/index.html

خوجـة، توفيق بـن أحمد، "المشروع العربي لتحسين جودة المرافق الصحية"، مجلس

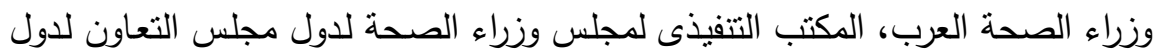

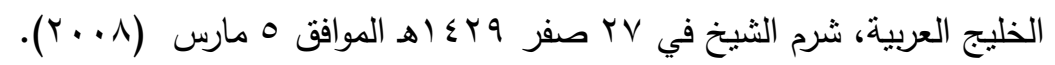

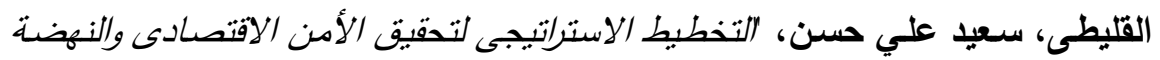

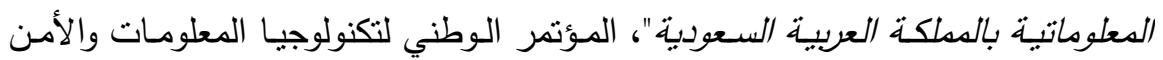

$$
\text { الوطني، الرياض، المملكة العربية السعودية ( V. . (Y). }
$$

Ward, J. and Peppard, J., "Strategic Planning for Information System", $3^{\text {rd }}$. ed., Cranfield School of Management, John Wiley \& Sons, Ltd. (2002).

Barksdale, S. and Lumd, T., "10 steps to successful strategic planning", American Society for Training \& Development (ASTD) Press (2006).

Macmillan, H. and Tampoe, M., "Strategic Management", Oxford University Press, [9] (2000).

Yank, J. A., McClellan, A. and Grace, K. Sp., "The Nonprofit Board's Role in Mission [1 • ] Planning, and Evaluation", $2^{\text {nd }}$. Ed.,Board Source (2009).

Allison, M. and Kaye, J., "Strategic Planning for Nonprofit Organizations: A Practical [11] Guide and Workbook", $2^{\text {nd }}$. Ed., John Wiley \& Sons, Inc. (2005).

Olsen, E., "Strategic Planning for Dummies", Wiley Publishing, Inc. (2007).

Mintzberg, H., "Tracking Strategies Towards a General Theory", Oxford University [ $\mathrm{l}$ ] Press, New York (2007).

Wittmann, R. G. and Matthias, R., "Strategic Planning", Replika Press Pvt. Ltd., India [ $\leqslant$ ] (2008).

Mintzberg, H. and Koehler, B., “Managing”, Publishers, Inc., California (2009). 


$$
\text { سعيد على حسن القلبطى و إبراهيم عبد العزيز الضراب }
$$

[7 1 ] ماهر، أحمد، "ذلبل المدبربن في كبفية إعداد الخطط والسباسات والاستراتبجيات"، القاهرة،

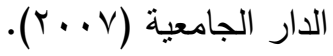

Kaufman, R., Browne, H. O., Watkins, R., Leigh, D. and Bass, J., "Strategic Planning [ I V] for Success: Aligning People, Performance, and Pay Offs", A Wiley Imprint (2003).

Daft, L., “Organizational Theory and Design”, St. Paul: West Co., USA (2001).

Wheelen, T.L. and Hunger, J.D., "Strategic Management and Business Policy", Pearson [1 9] Education Inc., Upper Saddle river, New Jersey, $10^{\text {th }}$. Ed. (2006).

Grant, R.M., "Contemporary Strategic Analysis: Concepts, Techniques, Applications", [ץ.] Blackwell Publishers Inc., $4^{\text {th }}$. Ed. (2002).

[ [Y] القليطى، سعيد علي حسن، وعابـ، سراج يوسف، نحو التخطيط الاستراتيجي والتحليل البيئي للنهضـة الاقتصـادية العربية لمواجهة المنافسـة العالمية فى ظل الظروف الراهنة، المؤتدر الدولي لجدعبة الهندسة الإدارية، المنافستة العالمبية: الفرص والتحديات، القاهرة

$$
\cdot(r \cdot v)
$$

[Yץ] توفيق، عبد الرحمن،"التخطبط الاستراتبيجي - هل بخلو المستقبل من المخاطر"، مركز

$$
\text { الخبرات المهنية للإدارة، القاهرة (ب . . r). }
$$

[Tr] بهادر، محسن عبدالرحمن، "أهمية التخطيط الاستراتيجي في الإدارة وتداعيات غيابه في

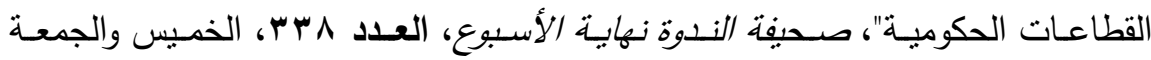

$$
\text { . }
$$

[ع بـ توفيت، عبـد الـرحمن، التفكير الاستراتيجي (المهارات والمدارسـات - أفكار عالمبية

معاصرة)"، إعداد مركز الخبرات المهنية للإدارة، إصدارات بميك، القاهرة (ب . . r).

[0ب] برايسون، جون م.، ترجمة محمد عزت عبد الموجود، "التخطبط الاستراتبجي للمؤسسات

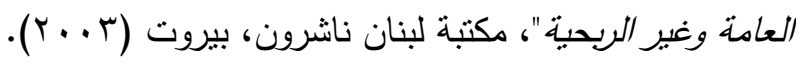

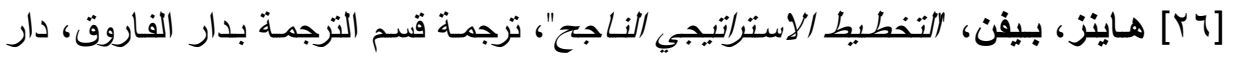

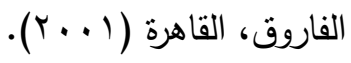

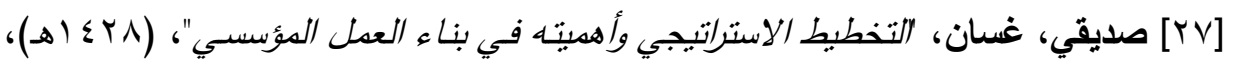

$$
\text { الموقع الإلكتروني "الموقع الإكتروني: حلقات": }
$$

http://www.halqat.com/Book-114.html

[^r^] القليطى، سعيد علي حسن، "التخطيط الاستراتيجي لتحقيق الأمن الفكري بالمملكة العربية السعودية"، المؤتدر الـوطني الأول للأكن الفكري (المفاهبم والتحديات)، كرسسي الأمبر

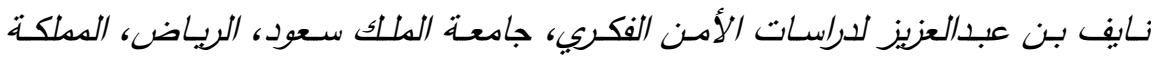

$$
\text { العربية السعودية (9 . . ب). }
$$


rAq التخطيط الإستراتيجي لهيكلة مشروعات طبية عربية مشتركة

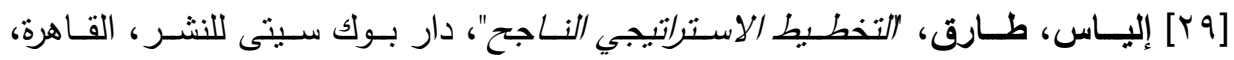
$\cdot(r . .9)$

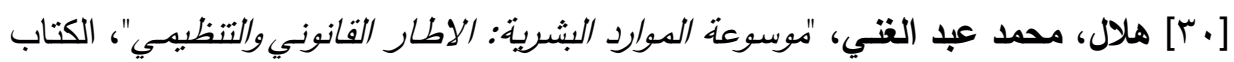

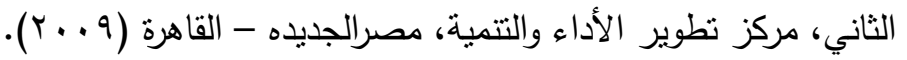

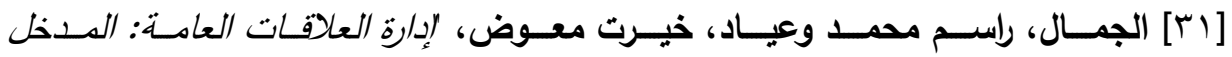

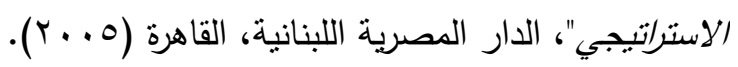




\title{
Strategic Planning for Structuring Arab Medical Joint Projects
}

\author{
Said Ali El-Quliti and Ibrahim Abdel-Aziz El-Darrab \\ Industrial Engineering Dept., King Abdulaziz University, \\ Jeddah, Saudi Arabia.
}

\begin{abstract}
This research is an attempt to touch the aspects of Arab joint cooperation in the medical field. It aims to expose the scientific, human and institutional resources enjoyed by the Arab world, and to clarify the obstacles that prevent achievement of the Arab joint cooperation. It is an attempt to take advantage of the ingredients and the positives that already exist and meet the challenges and disadvantages facing the joint Arab actions. It proposes an organizational structure for the Arab Health Organization to support, lead and supervise Arab medical joint projects, to work for the progress of medical scientific and research works in all the Arab countries, and to adopt a strategic planning as an access for such venerable targets.
\end{abstract}

Keywords: Strategic planning, Medical projects, Arab cooperation. 